\title{
Novel treatment opportunities for sulfur mustard-related cancers: genetic and epigenetic perspectives
}

\author{
Soheila Rahmani ${ }^{1} \cdot$ Mohammad Abdollahi $^{1,2}$ D
}

Received: 23 July 2017 / Accepted: 2 October 2017 / Published online: 10 October 2017

(C) Springer-Verlag GmbH Germany 2017

\begin{abstract}
Sulfur mustard (SM), also known as mustard gas, is a chemical weapon which by now has been used in many wars. The most concerning SM toxic effect is probable carcinogenicity. In this study, the genetic and epigenetic mechanisms of SM carcinogenicity, by focusing on treatment of SM-associated malignancies, particularly gene therapeutics, cancer vaccines, and epigenetic medications, have been criticized. The required data were collected through an organized search on valid scientific databases. For SM carcinogenicity due to acute or chronic exposure, the entire original and review articles were evaluated. In addition, studies on the therapeutic effects of available genetic and epigenetic medications were included. Currently, four gene therapeutics, two cancer vaccines with genetic bases, and seven epigenetic medications are available for cancer treatment. Genetic and epigenetic cancer treatments including Gendicine, Imlygic, Provenge, Cimavax-EGF, Azacitidine, Vorinostat, Romidepsin, and Belinostat will yield outstanding benefits for SM-exposed patients who suffer from cancer.
\end{abstract}

Keywords Cancer - Cancer vaccine - Epigenetic therapy · Gene therapy $\cdot$ Sulfur mustard

Mohammad Abdollahi

Mohammad@TUMS.Ac.Ir

1 Toxicology and Diseases Group, Pharmaceutical Sciences Research Center, Tehran University of Medical Sciences, Tehran, Iran

2 Department of Toxicology and Pharmacology, Faculty of Pharmacy, Tehran University of Medical Sciences, Tehran, Iran

\section{Introduction}

In virtue of its human toxicity, sulfur mustard (SM) has been used as a warfare agent in several conflicts since World War I (Borak and Sidell 1992). During World War II results of an accidental exposure to mustard demonstrated that its cytotoxic effects especially on rapidly proliferating cells may be helpful in some hematopoietic cancers such as lymphoma (Christakis 2011). Therefore, to improve antineoplastic effect and modulate its toxicity, a lot of mustard derivatives have been synthesized ever since (Amira et al. 2015; Mezencev et al. 2009; Sunters et al. 1992). However, there are some reports based on the secondary cancers as a result of the application of these agents in cancer treatment (Lee et al. 1982). Thus, chronic exposure to SM may also be contributed to the cancer progression (Saladi et al. 2006). The studies of evaluating the risk of cancer in British and Japanese factory workers engaged in the manufacturing of mustard gas revealed that mortality due to respiratory tract cancers was significantly higher in these population compared with non-exposed subjects. Moreover, small risk elevations for non-Hodgkin's lymphoma and leukemia were found among these workers (Easton et al. 1988; Nishimoto et al. 1986; Wada et al. 1968). Recent report from retired workers of these factories also indicated significant deaths from respiratory tract and liver cancers (Mukaida et al. 2017). Furthermore, it is assumed that acute exposure to SM can be a potential risk factor for cancer (Razavi et al. 2016). Regarding the report by National Academy of Sciences, US Department of Veterans Affairs, SM increases the risk of lung, skin, and hematopoietic cancers (Balali-Mood 2015). Epidemiologic studies on Iranian veterans showed significant rises of lung, skin, and blood cancers in this community. The most prevalent type of lung cancer observed was squamous-cell carcinoma. In the case of skin cancer, 
the most common cancers were squamous and basal cell carcinoma, and in the case of blood cancer, the most common ones were leukemia and cutaneous lymphoma (Emadi et al. 2008; Ghabili et al. 2010; Zafarghandi et al. 2013). Moreover, in a meta-analysis of SM carcinogenesis in Iranian veterans, it was found that the risk of carcinogenesis in this population is significantly greater than worldwide cancer incidence (Panahi et al. 2015). In another observational study, most frequent malignancies reported from American veterans were skin cancer followed by cancers of the lung, prostate, and bladder (Pechura and Rall 1993). Although melanoma was not reported in any literature, the skin complications in the veterans or factory workers such as scars, intertrigo, and hyperpigmentation might be the risk factors for melanoma (Elwood and Koh 1994; Emadi et al. 2008).

Notably, there is still no effective treatment for SM longterm complications despite more than 100 years of its use as a chemical weapon; further investigations are required to develop effective therapeutics. In the context of treatment of SM-related cancers to choose the appropriate treatment, it is important to learn the common therapeutic options and new opportunities. Currently, general treatments for cancer include chemotherapy, radiotherapy, hormone therapy, and mastectomy (dos Santos Guimarães et al. 2013; Falk 2009). Because of many adverse effects due to their poor selectivity, novel/efficient and safe treatments are necessary to be explored. Immunotherapy has recently proved its clinical utility with some approved medications in different kinds of cancers (Durrant and Scholefield 2009). Immunotherapy approaches have been demonstrated as suitable alternatives to the conventional cancer treatments. However, there are still some issues having to be dealt with in this regard (Michot et al. 2016). Other novel strategies predicted to be main parts of cancer therapy regimens include gene and epigenetic therapies. So far, gene therapy has shown remarkable benefits through specific targeting of tumor genes that promote malignant behavior and treatment resistance. In addition, gene therapy methods have been used to create recombinant cancer vaccines (Cross and Burmester 2006). Genetically engineered cancer vaccines have been proven highly efficient in clinical trials and can be potentially useful in treatment regimens of cancer patients (Palucka and Banchereau 2013). Aside from genetic view, epigenetic regulation disturbance has been found to be strongly associated with wide ranges of diseases specially cancer (Hodjat et al. 2017; Saeidnia and Abdollahi 2013). Accordingly, identification and targeting these perturbations would be a promising opportunity in cancer pathophysiology and treatment (Biswas and Rao 2017). Available gene and epigenetic therapeutics in the pharmaceutical market have achieved outstanding results in cancer treatment, alone or in combination with other regimens. They have shown significant improvement in the patient's quality of life. In the present study, genetic and epigenetic mechanisms of SM toxicity have been discussed; novel anticancer medications with genetic and epigenetic mechanisms as being the potential choices for treatment of SM-related cancers have been summarized and their safety and effectiveness have been reviewed (Fig. 1).

\section{Methods}

We conducted an organized search on Google Scholar, Science Direct, Up to Date, Medline, PubMed, Reaxys, Cochrane Library, and Scopus databases. For SM carcinogenicity due to acute or chronic exposure, the entire original and review articles were gathered and evaluated. Furthermore, studies which evaluated the therapeutic effects of

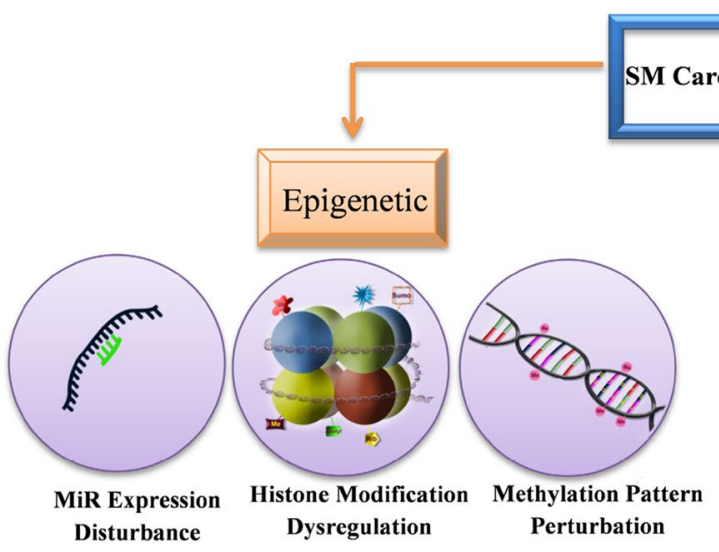

Fig. 1 Main mechanisms of sulfur mustard carcinogenicity. Sulfur mustard can exert its carcinogenesis effect through genetic and epigenetic mechanisms; genotoxicity of sulfur mustard can be attributed to alkylation of nucleic acids and subsequent inhibition of mitosis. Sulfur mustard exposure could also result in point mutation of cer-

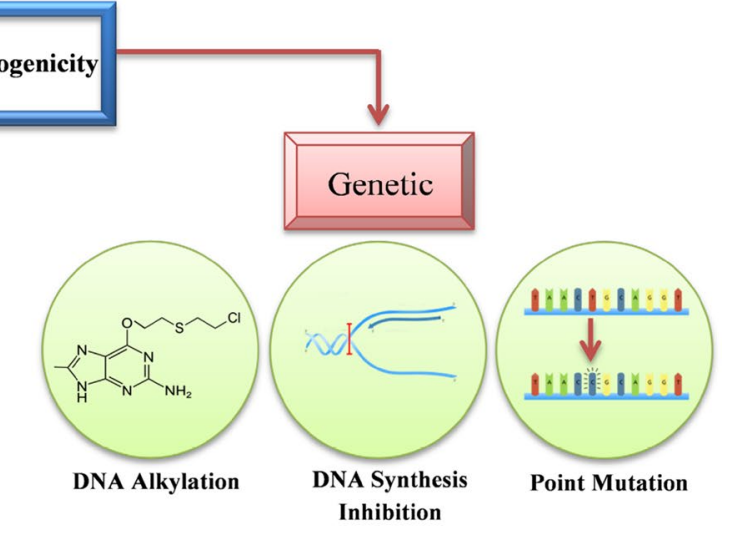

tain cell cycle regulatory genes such as P53. In epigenetic point of view, sulfur mustard can cause gene regulation perturbations in DNA methylation pattern, histone modification machinery, and non-coding RNAs expression. SM sulfur mustard, $M i R$ micro-RNA, DNA deoxyribonucleic acid 
available genetic and epigenetic medications on the pharmaceutical market for cancer treatment were included. For each medication, data of phase III clinical studies in various types of cancers alone or concurrently with other cancer therapeutic regimens were extracted. Safety and efficacy of these medications regarding to the patient's quality of life improvement were assessed and discussed separately. There was no limitation related to specific periods of time in searching databases.

\section{Genetic landscape}

Genetic toxicology describes the detrimental effects of chemical and physical agents on genetic material resulting in DNA damage and the development of subsequent malignancies. It has been well established that DNA damages which are not repaired can result in a high-frequency mutations that drive carcinogenesis process. These mutations are also responsible for long-term adverse effects of genotoxins and may be inherited through generations (Beedanagari et al. 2014).

SM is rated by the International Agency for Research on Cancer (IARC) as a human carcinogen (https://www.iarc.fr/) a matter that has been confirmed by epidemiological studies (Ghanei and Vosoghi 2002; Nishimoto et al. 1986). Following acute or chronic exposure, SM exerts its genotoxicity effects via interaction with chromosome. Through this reaction, DNA undergoes alkylation at specific regions that cannot be retrieved by DNA repair systems (Batal et al. 2014). For example alkylation of O6-guanine results in the formation of O6-ethylthioethylguanine which is a poor substrate for the DNA repair enzyme O6-alkylguanine-DNA alkyltransferase (Ludlum et al. 1986). It has been demonstrated that the alkylating agents produce a wide range of cytological effects in which initiating the apoptosis pathways seems to be the most crucial one. SM also can cause DNA crosslinking which can occur between two groups on the same polynucleotide chain or on two different chains. Cell death from DNA alkylation or cross-linking is delayed until the cell undergoes mitosis; chromosome breaks and inhibition of nucleic acid synthesis result in disruption of cell division process (Wheeler 1962). Although SM can react with RNA, proteins, and phospholipids, the general agreement is that DNA alkylation plays an important role in SM delayed toxic effects (Balali-Mood 2015; Khan et al. 2017a). Mutation in an oncogene or a tumor suppressor gene is one of the other proposed mechanisms for SM genotoxicity. In addition, SM exposure can lead to mutations in DNA repair genes. Mutation in these genes may augment the degree of DNA damage or accelerate mutation procedure (Behravan et al. 2013). Based on a report, double mutations (G:C to A:T) in lung cancer cases among Japanese mustard gas workers were significantly higher in comparison with non-exposed subjects (Takeshima et al. 1994). These mutations were also observed in Iranian veterans who had acute exposure to SM and suffered from lung cancer (Hosseini-khalili et al. 2009).

To completely elucidate the exact mechanism of SM genotoxicity, further researches are still required.

\section{Gene therapeutics}

Gene therapy is almost a new technique to treat a wide range of genetic disorders especially cancer by inserting a manipulated gene into the defective cell (Ginn et al. 2013). It includes two main strategies: (1) gene replacement, delivery of the normal gene into the cells to amend the function of the cell through correcting the functional protein and (2) gene silencing, the process in which an antisense RNA is used to silence an overexpressed gene by coupling with the specific site of mRNA through Watson and Crick base pairing which leads to inhibition of the transcription (Janssen et al. 2016). In a successful gene therapy approach, the gene therapeutics should be delivered safely and effectively to the target tissue. Delivery of the therapeutic genes can be accomplished by physical (ultra sound and electroporation) (Ibraheem et al. 2014), chemical (lipid and polymer-based gene vehicles) (de Ilarduya et al. 2010), and biological methods (bacteria, viruses, and exosomes) (Seow and Wood 2009). Viruses were the first vectors applied in gene therapy procedures. Despite the concerning issues about their safety, viruses have distinctive features that make them suitable gene delivery vehicles in clinical aspects and they are the only vehicles employed in the current gene therapy medications ( $\mathrm{Ni}$ et al. 2016). Up to now, several gene therapy clinical trials with various gene vehicles have been conducted in different types of cancers. Herein, worldwide available gene therapeutics for cancer treatment are summarized.

\section{Definitions}

Complete response (CR): the disappearance of all signs of cancer in response to treatment.

Partial response (PR): a decrease in the size of a tumor in response to treatment.

Stable disease (SD): the situation which no shrinkage or expansion of tumor is observable.

Overall survival (OS): the length of timle from the start of the treatment for cancer, that patients are still alive.

Overall survival rate (OSR): the percentage of people in a study who are still alive for a certain period of time after the initiation of treatment.

Objective response rate (ORR): the percentage of patients who have a measurable reduction in tumor size after the initiation of treatment. 
Median survival time (MST): the time when half the patients are expected to be alive after certain treatment.

Disease-free survival (DFS) or relapse-free survival (RFS): the length of time after a treatment regimen that the patient survives without any signs or symptoms of the cancer.

Progression-free survival (PFS): the length of time during and after the treatment initiation that patients do not experience disease development.

Durable response: a long-lasting positive reaction to treatment which lasts at least a year.

Durable response rate (DRR): the percentage of patients who have a long-lasting positive reaction to treatment.

\section{Gendicine $^{\mathrm{TM}}$}

Gendicine ${ }^{\mathrm{TM}}$ was the first worldwide gene therapeutic approved by the Food and Drug Administration of China (CFDA) in 2003 for the treatment of head and neck squamous-cell carcinoma (HNSCC) and became the world's first cancer gene therapy medication. It contains p53 tumor suppressor gene delivered by a recombinant adenoviral vector (Ad-p53) (Pearson et al. 2004). P53 gene is involved in different cell cycle regulatory mechanisms such as apoptosis, cell senescence, differentiation, angiogenesis, cell migration, cell metabolism, and DNA repair. Its mutation or deletion is observed in several malignancies. Therefore, many clinical trials including head and neck squamous-cell carcinoma, lung, breast, pancreatic, and liver cancers focus on overexpressing p53 to restore its function and demolish the tumor cells (Bressy et al. 2017). However, the efficacy of this transfection is not that simple and depends on many factors. In case of Ad-p53, the expression level of type $5 \mathrm{Ad}$ receptors is one of the determinative factors in therapeutic efficacy. The poor therapeutic effect is observed in tumor cells with low levels of Ad 5 receptors. For instance, production of Ad-neutralizing antibodies, which are promoted post-administration of Ad, is a limitation of transfection. It has been reported that about $60 \%$ or more of the world population are are positive for anti-Ad5 antibody before any administration. Therefore, level of neutralizing antibody may rise after a single Ad administration. Furthermore, based on preclinical and clinical researches, Ad-p53 may be more effective in tumors with mutated p53 due to intact downstream pathways. In this regard, wild-type p53-bearing tumor cells might have mutated p53-downstream cascades that give rise to treatment resistance despite super-induction of p53. Tumors with epigenetically dysregulated p53 gene have shown minimal therapeutic response to Ad-p53 similar to wild-type p53-bearing tumors (Ma et al. 2008).

Gendicine approval was based on small phase II clinical trials that showed its efficacy in $64 \%$ of head and neck cancer patients with concurrent radiotherapy (Ma et al. 2008).
Meta-analysis of 12 clinical trial results revealed that complete remission $(\mathrm{CR})$ and overall response $(\mathrm{OR})$ were significantly improved in the combinational regimen of Gendicine and conventional chemotherapy (radiotherapy and chemotherapy) and patients who received the combination therapy (Gendicine and conventional therapy) showed significantly prolonged 1- and 2-year overall survival (OS) and 2-year disease-free survival (DFS) (Yuan et al. 2016). Phase III clinical study of combination of Gendicine with the conventional chemotherapy regimen in advanced (stage III or IV) squamous oral cancer treatment revealed that intraarterial infusion of Gendicine with concurrent chemotherapeutics, significantly improved the survival rate of patients with stage III but not stage IV oral cancer compared with chemotherapy regimen alone. Phase I clinical study of Gendicine in 15 lung cancer patients with intratumoral injection indicated that $46.7 \%$ of assessed patients had stable disease (SD) and $33.3 \%$ showed partial response (PR). In another phase I clinical study, 15 patients with advanced lung cancer were treated with Gendicine in combination with the conventional chemotherapy and $46.7 \%$ of them responded to the regimen partially or completely (Zhang and Lu 2012).

Advexin $^{\mathrm{TM}}$ (Contusugene Ladenovec Gendux) is another Ad-p53 gene therapeutic for treatment of HNSCC which its manufacturer, Introgen Therapeutics, claims that SiBiono's Gendicine is similar to its own investigational medicine. Gendicine and Advexin are essentially the same medications. Even so, Advexin was not approved by the U.S. FDA or European Medicine Agency (EMA) due to the lack of safety and efficacy benefit (European Medicines Agency 2009).

\section{Rigvir $^{\mathrm{TM}}$}

Oncolytic viruses are therapeutics that have either been naturally selected or genetically manipulated to specifically replicate in tumor cells. The selectivity of oncolytic viruses is originated from the specific mutations occurred in cancerous cells (Bell et al. 2003). Rigvir ${ }^{\mathrm{TM}}$ was the first commercial oncolytic virus which was approved in 2004 by the State Agency of Medicines of the Republic of Latvia for treatment of various types of malignancies. It is a non-genetically modified, non-pathogenic enterovirus which due to its potential oncolytic activity can induce cancerous cell apoptosis regardless of the tumour type. According to its receptor specificity for CD55, a receptor associated with cancer immunoescape in several malignancies, Rigvir can attach to the cancer cell membrane and block the receptor which results in the expose of tumor cells to the immune system and subsequently tumor cell destruction by means of cytotoxic $\mathrm{T}$ lymphocytes (Pio et al. 2014). Furthermore, activation of humoral immunity and induction of interferon simultaneously with activation 
of cellular T-system immunity are the other immunomodulatory mechanisms of Rigvir. Its randomized clinical trials in almost 2000 patients with different malignancies such as melanoma, prostate, and lung cancers revealed that disease progression-free survival was significantly increased in Rigvir administered patients (Alberts et al. 2016; Babiker et al. 2017; Bruvere et al. 2006; Donina et al. 2015).

\section{Oncorine $^{\mathrm{TM}}$}

H101 is another oncolytic virus type-5 adenovirus (Ad5) which two segments of its genome have been deleted: one is responsible for adenovirus virulence and the other is in control of p53-binding and inactivation. By deletion of the latter, the virus would not be able to inactivate $\mathrm{p} 53$ for efficient replication in normal cells. On the contrary, once a cancerous cell with the p53 mutated gene is infected by the virus, it would be exploded as a result of virus replication. In 2005, Chinese FDA (CFDA) approved Sunway's H101 under the trade name of Oncorine ${ }^{\mathrm{TM}}$, for treatment of head and neck squamous-cell carcinoma. Pivotal study for its approval was a phase III clinical trial in which H101 was added to the chemotherapy regimen of $160 \mathrm{HNSCC}$ patients; the results showed that $74 \%$ of enrolled patients experienced a reduction in the size of tumors compared to $40 \%$ of patients receiving chemotherapy alone (Ma et al. 2008). In another phase III clinical study, combination of Oncorine and cisplatin-fluorouracil regimen in treating squamous-cell cancer of head and neck or esophagus improved overall response rate approximately twofold compared to cisplatin-fluorouracilalone (78.8 vs. $39.6 \%$ ). Nevertheless, the therapeutic efficacy of combination regimen of Oncorine-adriamycin-fluorouracil did not differ from adriamycin-fluorouracil alone (Xia et al. 2004). Results of a retrospective study revealed that Oncorine could provide a 7-month survival benefit, but this improvement was not significant. To increase survival benefit, the company started new phase III clinical studies with a greater number of eligible patients (Guo and Xin 2006).

The efficacy of Oncorine ${ }^{\mathrm{TM}}$ in combination with chemotherapy regimen in lung cancer treatment was evaluated in a phase I clinical study. Results indicated that Oncorine in lung cancer was safe, but the efficacy was not as great as in the case of head and neck cancer (Ma et al. 2008).

Oncorineis analogous to Onyx-015 was made by Onyx Pharmaceuticals. Whereas U.S. FDA did not approve Onyx-015 for treatment of HNSCC due to the limited benefit on patients' life extension, Oncorine manufacturer bought the worldwide rights to Onyx-015 technology from Onyx in 2005 and succeeded to gain CFDA approval (Wirth and Ylä-Herttuala 2014).

\section{Imlygic $^{\mathrm{TM}}$}

Talimogene laherparepvec or T-VEC (Imlygic ${ }^{\mathrm{TM}}$, formerly called OncoVex $\left.{ }^{\mathrm{GM}-\mathrm{CSF}}\right)$ is the third gene therapy medication with a virotherapeutic strategy; it contains an oncolytic herpes simplex virus which has been genetically engineered, so that the virulence region of the genome has been replaced by the gene of human granulocyte-macrophage colony-stimulating factor (GM-CSF) to improve host immune defense against tumor cells. Hence, similar to Rigvir ${ }^{\mathrm{TM}}$, it has dual mechanisms: virotherapy, selective infection and demolition of cancerous cells which have low levels of protein kinase R (PKR) and dysfunctional type 1 interferon signaling elements, immunotherapy, and subsequent exposure of tumor-associated antigens to the immune system which is enhanced by viral expression of GM-CSF. Imlygic was approved in 2015 by TGA (Therapeutic Goods Administration of Australia), U.S. FDA, and EMEA. It is indicated for the local treatment of unresectable cutaneous, subcutaneous, and nodal lesions in patients with recurrent melanoma after the initial surgery. The pivotal study for its approval was a phase III clinical trial in which late stage melanoma patients with unresectable but accessible lesions received T-VEC or GM-CSF. Subjects receiving T-VEC had a significantly increased durable response and overall response rate compared to GM-CSF. Besides, $26.4 \%$ of patients in T-VEC group experienced a tumor size reduction compared to $5.7 \%$ of cases in GM-CSF group. In this trial, T-VEC was associated with a $10.8 \%$ complete response rate, which included regression in injected and non-injected lesions compared to $1 \%$ complete response rate for GM-CSF. However, it has not been shown to improve overall survival or prevent metastases (Andtbacka et al. 2014; Kaufman and Bines 2010).

The presence of melanoma antigen, which is recognized by $\mathrm{T}$ cells (MART-1) specific $\mathrm{CD} 8^{+} \mathrm{T}$ cells in tumors injected with T-VEC, demonstrates tumor-specific immune responses (Johnson et al. 2015; Kohlhapp and Kaufman 2016).

Currently, T-VEC is being studied in combination with other immunotherapies such as monoclonal antibodies and also in other solid tumors such as head and neck cancer, and preliminary data have shown promising results (Doepker and Zager 2016; Greig 2016) (Table 1).

\section{Cancer vaccines}

The idea of cancer vaccine comes from the use of tumor antigens to augment immune recognition of cancerous cells, and thus, specific lymphocytes can target these tumor antigens and provoke T-cell-mediated tumor eradication. Therapeutic cancer vaccines have been shown to be much less toxic than the conventional therapies. Thus, they can 
significantly improve the patient's quality of life. As the predominant antigen presenting cell, application of dendritic cell in cancer vaccines is a promising option for therapeutic vaccine development. Genetic modification of dendritic cells to express tumor antigens and/or immunomodulatory cytokines can improve their capacity to stimulate a strong antitumor immune response and subsequent tumor destruction (Arnouk 2012; Farkas et al. 2006). Herein, genetically engineered therapeutic cancer vaccines entering pharmaceutical market have been reviewed.

\section{Cimavax-EGF}

Cimavax-EGF is a therapeutic cancer vaccine used in nonsmall cell lung cancer (NSCLC). It comprises human recombinant epidermal growth factor (EGF) which leads to EGF antibody production in the patient's body and subsequent blockade of epidermal growth factor binding to its receptor, EGFR, which is expressed in $40-80 \%$ of lung cancer cells. Since this blockade only results in tumor growth inhibition and the vaccine does not exert any cytotoxic effect against tumor cells, it can be considered as a preventive vaccine rather than a therapeutic one. Phase III clinical trial results revealed that median survival time was significantly increased in patients receiving the vaccine as maintenance therapy compared with control group (12.43 vs. 9.43 months) (Rodriguez et al. 2016). Cimavax-EGF has been developed in Cuba; it was approved by the Cuban regulatory authority in 2008 for the use in adults with non-small cell lung cancer. Recently, U.S. FDA approved its clinical trial on U.S. patients.

\section{Provenge $^{\mathrm{TM}}$}

Sipuleucel-T was the first therapeutic cancer vaccine approved by U.S. FDA in 2010 for the treatment of asymptomatic or minimally symptomatic metastatic hormone refractory prostate cancer under the trade name of Provenge ${ }^{\mathrm{TM}}$. It is composed of autologous dendritic cells isolated from prostate cancer patients and are genetically manipulated with the purpose of presenting prostatic acid phosphatase (PAP) with concurrent GM-CSF gene expression. PAP antigen is a tumor-specific antigen which is expressed by almost $95 \%$ of prostate cancer cells. Afterward, the cells transferred back into the patient's body, present the PAP-derived epitopes to the immune system leading to the activation of PAP-specific cytotoxic T-cell immune responses. In phase III randomized clinical trials, Sipuleucel-T showed a statistically significant median overall survival of 25.9 months compared with placebo (Small et al. 2006). Men receiving Sipuleucel-T experienced more than $20 \%$ mortality risk reduction compared with the control group (Higano et al. 2009; Kantoff et al. 2010). The efficacy of vaccination in androgen-dependent 
prostate cancer was evaluated in a randomized phase III clinical trial and the results indicated that Sipuleucel-T can produce a long- lasting T-cell activation for 67.4 months (Beer et al. 2011) (Table 2).

Taking collectively, intratumoral injection of therapeutic medications can be a favorable route of administration with minimal therapeutic dose and the slight systemic adverse events in the case of accessible tumors. Most of the current gene therapeutics including Gendicine, Oncorine, and Imlygic serve this goal in the treatment of unresectable or locally advanced stage tumors such as squamous head and neck cell carcinoma and melanoma. Based on the available literature, Gendicine can strongly eradicate the tumor in combination with radiation or chemotherapy in SHNCC and other solid tumors such as lung and liver cancer. Significant prolongation of overall survival and disease-free survival in the patients participating in Gendicine clinical trials indicates the potential effective role of Gendicine in the solid tumors treatment regimens. In addition, the most common adverse effect the enrolled patients in these clinical trials experienced was the slight immune reaction. On the other hand, Oncorine only succeeded in combination of certain chemotherapy regimens, and despite significant overall response, it could not be able to improve overall survival in SHNCC patients. At the current time, Imlygic, the only U.S. FDA gene therapeutic for melanoma treatment, with dual mechanisms of action and intralesional route of administration has attained outstanding durable responses in clinical trials and also in the market. It can be considered as a viable monotherapy option or in combination with other immunotherapeutics, in patients with recurrent and advanced unresectable skin tumors who have failed the other therapies. In the case of Rigvir, another therapeutic oncolytic virus indicated for melanoma and other solid tumors; the lack of statistical analyses on its outcome in clinical studies makes it hard to decide about its precise efficacy. However, it could be considered as one of the treatment options due to its ease of administration, good safety profile, and low price. Therapeutic cancer vaccines with their ability to augment the immune system recognition are promising candidates for cancer immunotherapy as alternative therapeutic options in late stage advanced cancers. Provenge is the only available therapeutic cancer vaccine today, which is indicated in hormone refractory prostate cancer. It possesses a lot of advantages, including prolongation of patient's overall survival, improvement of the patient's quality of life, and satisfactory safety profile. In spite of these, delayed effect of immune system provocation and the absence of prognostic parameters to evaluate the beneficial effect of the vaccine in each individual patient may be the major drawbacks of Provenge or other clinical therapeutic cancer vaccines. Moreover, because of the high costs of vaccination schedules only small fraction of patients can afford this treatment. Cimavax-EGF, another cancer vaccine, which has only been available in Cuba, can be considered as a safe preventive cancer vaccine in early stage lung cancer or other solid tumors with EGF overexpression. Cimavax-EGF with its reasonable cost-effectiveness can be regarded as a favorable therapeutic choice in cancer patients.

\section{Epigenetic landscape}

Epigenetics refers to the study of inheritable changes in one's phenotype which are not related to DNA sequences. It consists of three main gene regulation pathways, namely, DNA methylation, histone modification, and non-coding RNAs. DNA methylation is a process in which one methyl group is transferred to the cytosine nucleotide via DNA methyl transferase enzymes (DNMTs). It can regulate the gene expression by silencing or upregulating the gene depending on the loci of methylation. Histone modification is used to regulate the chromatin and consequently the gene. This is done by designing different chemical groups that can attach to the specific amino acids in the tail region of the histone. One of the most common histone modifications is histone acetylation and deacetylation which result in gene activation or suppression, respectively, and

Table 2 Therapeutic cancer vaccines in the pharmaceutical market

\begin{tabular}{|c|c|c|c|c|c|}
\hline Cancer vaccine & Approval year & Indication & Dose schedule & Common adverse reactions & References \\
\hline Cimavax-EGF & 2008 & NSCLC & $\begin{array}{l}\text { Induction dose of } 4 \text { IM } \\
\text { injections ( } 2 \text { deltoid and } \\
2 \text { gluteus sites) every } \\
2 \text { weeks for } 8 \text { weeks ( } 4 \\
\text { doses) and then monthly } \\
\text { administration }\end{array}$ & $\begin{array}{l}\text { Fever, headache injection- } \\
\text { site pain, vomiting }\end{array}$ & Rodriguez et al. (2016) \\
\hline Sipuleucel-T (Provenge ${ }^{\mathrm{TM}}$ ) & 2010 & Prostate cancer & $\begin{array}{l}3 \text { Doses of IV infusion at } \\
\text { approximately 2-week } \\
\text { intervals }\end{array}$ & $\begin{array}{l}\text { Fever, headache, influenza- } \\
\text { like syndrome, hyperten- } \\
\text { sion }\end{array}$ & $\begin{array}{l}\text { Higano et al. (2009), } \\
\text { Kantoff et al. (2010) }\end{array}$ \\
\hline
\end{tabular}

$E G F$ epidermal growth factor, $N S C L C$ non-squamous-cell lung cancer, $I M$ intramuscular, $I V$ intravenous 
catalyzed by two groups of enzymes called histone acetyl transferase (HAT) and histone deacetylase (HDAC). Posttranscriptional gene regulation is provided by non-coding RNAs; micro RNAs (miRNA) are one of the major subtypes of non-coding RNAs, which interfere with the translation procedure through binding with mRNAs and negatively regulating gene expression. Each of these gene regulation machineries can be influenced by environmental factors such as diet, smoking, climate, and toxicants (Hodjat et al. 2017; Khan et al. 2017b). It is revealed now that besides genetic mutations, epigenetic dysregulations such as hypermethylation of tumor suppressor and repairing genes and subsequently their inactivation have become the major stimulus of human cancers (Biswas and Rao 2017). SM along with other toxicants can cause epigenetic aberrations which today are considered as the main suspect for its chronic toxicity and long-term complications such as cancer (Korkmaz et al. 2008). Mustard derivatives can lead to rise in HDAC levels in respiratory system resulting in suppression of a group of genes including those of antioxidants and anti-inflammatory proteins (Korkmaz et al. 2016). One of the major HDAC subgroup is HDAC-2; dysregulation of HDAC-2 is contributed to inflammatory lung diseases such as chronic obstructive pulmonary disease (COPD) and asthma which are the main complications in mustard lung individuals. Moreover, increased level of HDACs is one of the common epigenetic dysregulations in various malignancies (Sharma et al. 2010; Shinjo and Kondo 2015). Endothelial cell exposure to SM also leads to overexpression of Wolf-Hirschhorn syndrome (WHSC1) gene, one of the histone methyl transferases undergoing dysregulation in leukemia and many solid tumors such as skin, lung, prostate, and ovarian cancers (Kassambara et al. 2009; Steinritz et al. 2016). In lung epithelial tissue, SM stimulates the expression of proinflammatory genes such as MAPK and NFKB and subsequently leads to epigenetic regulatory disturbance such as HAT and HDAC induction and hypomethylation of activator protein 1 (AP-1) (Imani et al. 2015). According to a recent study, particular inflammatory molecular pathways may have an important role in carcinogenesis. The model designed in this study indicates that a semi-stable epigenetic change may initiate a process that leads from inflammation to transformation associated with cancer. This transformation is irreversible unless any of the accelerator molecules of the process such as miR21 or NFKB is transiently inhibited (Hunter 2015). In this regard, the association between SM-induced inflammation in lung and other tissues and malignancies incidence can be explained. Furthermore SM in high doses has limited effect on DNMT, but in low doses induces upregulation of DNMT1 leading to aberrant DNA methylation in skin and lung tissue. It has also been postulated that SM-induced
DNA demethylation is due to rise in DNMT1 because of its potential demethylation activity (Korkmaz et al. 2008; Steinritz et al. 2016).

Squamous-cell carcinoma is one of the types of lung cancer with high incidence rates in respiratory malignancies of SM-exposed patients. Global hypoacetylation as a result of HDAC overexpression, upregulation of DNMT1, DNMT3a, and DNMT3b, and subsequent gene hypermethylation are observable in this type of cancer (Chaisaingmongkol et al. 2012; Langevin et al. 2015). Significant DNA hypermethylation is also involved in skin cancer, leukemia, and many other types of malignancies (Chiam et al. 2014; de Unamuno et al. 2015; Peirs et al. 2015; Wouters and Delwel 2016). P53 is one of the main tumor suppressor genes mutated in many cancerous cells (Ananthaswamy et al. 1997; Bodner et al. 1992; Kupryjańczyk et al. 1993); it has been found today that $\mathrm{p} 53$ is far more susceptible to mutation in methylated loci $(5 \mathrm{meC})$ in comparison with unmethylated regions. Furthermore, DNA methylation can enhance the carcinogenicity of environmental mutants (Langevin et al. 2015). Moreover, the significant role of miRNAs in cancer has been highlighted by the identification of alterations in miRNA processing machinery in tumor cells. Several miRNAs are found to be misregulated in most of lung cancer patients; miR-21, miR-106a, miR-126, miR-185, miR-210, miR-15, miR-196a, and miR-200b are some of these examples. MiR210 or hypoxamir is responsible for cell cycle control and proliferation (Banerjee et al. 2011) and is overexpressed in malignancies such as skin and lung cancers; also in the tumor microenvironment, it induces immunosuppression response against cancerous cells (Noman et al. 2012). In a study, miR-210 level in keratinocyte cell line cultured in hypoxia significantly increased after exposure to SM (Deppe et al. 2016). The miRNA level of endothelial cells in an animal study after SM exposure was evaluated. It was found that miR-92a is the most impacted miRNA in SMexposed mice (Schmidt et al. 2016). MiR-92a's elevated level is seen in many types of tumors such as lung cancer, colorectal cancer, and leukemia, and also is correlated with poor disease prognosis (Liu et al. 2013; Ranade et al. 2010; Tanaka et al. 2009). MiRNAs also have a crucial impact on cutaneous T-cell lymphoma (CTCL) and may be involved in its pathogenesis. Studies have indicated that expression of some miRNAs especially miR-155 and miR-92a is significantly elevated in skin lesions of CTCL patients (Giorgio et al. 2016). Moreover, miR-143 expression has been found to reduce significantly in SM-exposed individuals (Khafaei et al. 2015). Dysregulation of this miRNA is also contributed to cancer initiation and progression; its expression is reduced in many types of cancers (Akao et al. 2006). MiR21 and miR-203 are other miRNAs misregulated in SMexposed individuals; however, there is no positive correlation between their dysregulation in malignancies and SM's 
toxicity (Chang et al. 2015; Chen et al. 2012; Greither et al. 2010; Langevin et al. 2015; Valizadeh et al. 2015). Putting all these together, it can be assumed that comprehension of exact epigenetic mechanisms of SM's carcinogenicity is too complicated and further exploration is still warranted (Chappell et al. 2016).

\section{Epigenetic medications}

In view of the fact that in nearly all malignancies, overexpression or mutation of DNMTs and HDACs is the major epigenetic dysregulation, these two enzymes can be promising candidates as therapeutic targets in cancer epigenetic therapy. Currently, there are seven approved epigenetic medications in the pharmaceutical market, which two of them are DNMT inhibitors and the others act as inhibitors of HDAC.

DNA methyltransferase inhibitors (DNMTi) known as hypomethylating or demethylating agents were initially developed as cytotoxic agents to be used in cancer at higher doses, but further studies revealed their epigenetic mechanisms at low doses (Diesch et al. 2016). The two hypomethylating agents Azacitidine and Decitabine are the most frequently used medications in the United States and Europe for the treatment of elderly AML patients who are not eligible for intensive chemotherapy regimens (124).

\section{Azacitidine (Vidaza ${ }^{\mathrm{TM}}$ )}

Azacitidine (AZA) is a cytidine nucleoside analogue which was approved by U.S. FDA in 2004 for use in patients with myelodysplastic syndrome (MDS) under the trade name of Vidaza ${ }^{\mathrm{TM}}$ (Kaminskas et al. 2005b). In MDS, the bone marrow is impaired and produces large number of immature blood cells called blast cells. About one-third of MDS cases progress to acute myeloid leukemia (AML) (Bennett et al. 1982). Vidaza ${ }^{\mathrm{TM}}$ was also approved in EU (European Union) in 2008 for the treatment of MDS adult patients who are not eligible for hematopoietic stem cell transplantation (HSCT), chronic myelomonocytic leukaemia (CMML) with 10-29\% marrow blasts without myeloproliferative disorder, and AML with 20-30\% blasts (European Medicines Agency 2008). Azacitidine is activated in the cell via phosphorylation and at low doses inhibits DNMT1 activity during replication through integration into DNA and induces DNA hypomethylation and DNA damage. Subsequent DNA hypomethylation might activate formerly silenced genes such as tumor suppressor genes. In rapidly proliferating cells, the cytotoxicity of Azacitidine may also be attributed to the formation of covalent bond between DNMT1 and Azacitidine incorporated into DNA (Issa et al. 2005).
Since it is a ribonucleoside, AZA is able to integrate into RNA and interfere with protein synthesis and this might be another mechanism of its cell death activity (Hollenbach et al. 2010). In addition to upregulation of tumor suppressor genes, AZA can also change the expression of many other genes especially immunomodulatory pathway genes and this can be beneficial to cancer immunotherapy (Li et al. 2014). Melanoma-associated antigen (MAGE) family is one of the cancer associated antigens which its overexpression has been reported in many solid tumors including melanoma, breast and lung cancers, and also hematopoietic malignancies such as AML. Preclinical studies showed that DNMT inhibitors such as AZA are able to augment the $\mathrm{CD} 8^{+}$cytotoxic T lymphocyte (CTL) responses against tumor cells via upregulation of MAGE genes in AML patients (Goodyear et al. 2010). Moreover, the immunomodulatory effect of AZA has been evaluated in a phase I clinical study in which AZA was administrated post-donor lymphocyte infusion (DLI) after allogeneic stem cell transplantation (allo-SCT) in eight cases of relapsed AML to reduce the risk of graft vs. host disease (GVHD). The results revealed that AZA by increasing the $\mathrm{T}$ regulatory cells could lower the rate of graft vs. host interaction without any reflex on graft vs. leukemic cells and also could reduce the death rate from acute GVHD. The possible mechanism proposed for this effect is the activation of fork-head box P3 (FOXP3) gene in allogeneic lymphocytes $\left(\mathrm{FOXP}^{-}{ }^{-}\right.$) through hypomethylation and converting them into T-regs $\left(\mathrm{FOXP}^{+}\right)$(Ghobadi et al. 2016). Results of a phase III clinical experiment showed superiority of AZA over conventional chemotherapy in elderly AML patients with blast count $>30 \%$. Overall survival rate in AZA group was approximately twofolds higher than chemotherapy group and rate and duration of serious adverse effects were lower in AZA arm compared to the conventional chemotherapy (Dombret et al. 2015). In another phase III clinical study, the incidence rate of treatment related adverse events and hospitalization in elderly AML patients received AZA and the conventional chemotherapy regimen was evaluated. The results indicated that AZA prolonged overall survival vs. conventional care regimens in elderly patients with AML by 3.9 months and the incidence rate of treatment related adverse events hospitalization reduced 55\% in AZA group (Seymour et al. 2017). Furthermore, analyses of the results of two recent phase III clinical studies revealed that AZA can be considered as a front-line treatment option for AML patients due to the improvement of overall survival rate (Pleyer et al. 2017). Meanwhile, oral AZA safety and efficacy are being investigated in randomized clinical trials for maintenance therapy in patients with MDS or AML. Studies have shown that oral AZA has been generally well tolerated and 
has had a safety profile similar to injectable AZA (Cogle et al. 2015).

\section{Decitabine (Dacogen ${ }^{\mathrm{TM}}$ )}

Decitabine (DAC) is another DNMT inhibitor which is approved by U.S. FDA in 2006 under the trade name of Dacogen $^{\mathrm{TM}}$ for use in MDS (U.S. Food and Drug Administration 2005). It also received marketing authorization by EMA in 2012 for treatment of MDS and AML in adults (European Medicines Agency 2012). Decitabine mechanism of hypomethylation is similar to AZA except it is a deoxyribonucleoside and can only integrate into DNA (Momparler 2005). Results of a randomized multicenter phase III clinical trial of Decitabine vs. treatment choice (cytarabine) in elderly patients ( $>70$ years) showed that despite more than $90 \%$ deaths of enrolled patients, Decitabine improved response rate over the standard regimen (the complete response rate plus near complete response rate was $17.8 \%$ with decitabine vs. $7.8 \%$ with cytarabine) (Kantarjian et al. 2012). In another phase III clinical study, DAC increased overall survival after 6 months of treatment compared with low-dose cytarabine or supportive care in older patients with newly diagnosed AML (Thomas et al. 2014). In addition, results of a meta-analysis of comparison between efficacy of AZA and DAC in treatment of MDS revealed that partial response, hematologic improvement, and overall response rates for AZA were significantly higher than for DAC; however, complete response and grade 3 or 4 hematologic toxicity did not differ for these two medications. In contrast to DAC, AZA significantly improved overall survival and time to AML transformation compared to best supportive care. Moreover, among patients with higher risk or older than 75 years, administration of AZA had promising results. Concluding from these data, AZA's efficacy is superior to DAC and it is recommended as the first-line hypomethylating agent for MDS, especially in elderly patients or those with high risk (Scott 2016; Xie et al. 2015). Furthermore, in accordance with a study evaluating the efficacy of AZA and DAC in sequential treatment of AML patients, it is revealed that the administration of AZA after DAC treatment failure yielded greater response rate compared with DAC as a second-line agent (Apuri et al. 2017).

\section{Vorinostat (Zolinza $\left.{ }^{\mathrm{TM}}\right)$}

Much the same as DNMT inhibitors, HDAC inhibitors (HDACi) were first characterized for their antitumour activity in vitro before unraveling their exact epigenetic mechanism (Ceccacci and Minucci 2016). Vorinostat (suberoylanilide hydroxamic acid, SAHA) is the first histone deacetylase inhibitor (HDACi) approved in 2006 by U.S. FDA in the form of oral capsule under the trade name of Zolinza ${ }^{\mathrm{TM}}$ for the treatment of cutaneous manifestations in patients with cutaneous T-cell lymphoma (CTCL) who have progressive, persistent or recurrent disease on or following two systemic therapies (Mann et al. 2007). Vorinosat suppresses the activity of HDAC1, HDAC2 and HDAC3 (Class I), and HDAC6 (Class II). Inhibition of histones hypoacetylation is associated with an open chromatin structure and transcriptional activation. Although the exact mechanism of the antineoplastic effect of Vorinostat has not been fully understood, it is hypothesized that Vorinostat administration causes accumulation of acetylated histones and induces the transcription of genes regulating growth arrest, caspase-dependent apoptotic cell death, and/or caspase-independent autophagic cell death of transformed cell (Duvic and Vu 2007). For example, one of the genes most commonly induced by Vorinostat encodes p21 which is a regulator of cell cycle progression. Moreover, similar to AZA, HDAC inhibitors also can upregulate the immune pathway genes ( $\mathrm{Li}$ et al. 2014). One of the other underlying mechanisms of cytotoxicity of HDACi may be the induction of oxidative damage. Since the transformed cells are more susceptible to oxidative damage, selectivity of HDACi might be attributed to this procedure. Vorinostat administration particularly results in the production of reactive oxygen species in transformed cells in association with diminished induction of the antioxidant enzyme thioredoxin. Consequently, Vorinostat and other HDACi possess antitumour activity especially against tumour types vulnerable to oxidative injury (Grant et al. 2007). Supporting approval studies were two open-labeled multicenter phase II clinical trials in which oral Vorinostat was given to patients with advanced CTCL who had progressive, persistent, or recurrent disease on or following two systemic therapies. Approximately $30 \%$ of patients had at least a partial response in both studies and this rate is comparable to common approved medications indicated for cutaneous manifestation of CTCL (Mann et al. 2007). The addition of Vorinostat to standard regimen with cytarabine and idarubicin AML was recently evaluated in a phase II study and no significant toxicity related to Vorinostat was found. Further studies for evaluation the efficacy of this combination are warranted (Ungewickell and Medeiros 2012a, b). Phase III clinical study of the addition of Vorinostat to Bortezomib as an approved medication for multiple myeloma showed that even with the improvement of cancer progression-free survival, Vorinostat clinical benefit in multiple myeloma necessitates further researches (Dimopoulos et al. 2013).

\section{Romidepsin (Istodax ${ }^{\mathrm{TM}}$ )}

Romidepsin, sometimes referred to as depsipeptide (trade name Istodax ${ }^{\mathrm{TM}}$ ), is another HDACi approved by U.S. FDA in 2009 for treatment of CTCL in patients who received at least one prior systemic therapy (Hughes 2010). Its approval 
was based on two pivotal randomized open-labeled phase II clinical studies which in both approximately $34 \%$ of enrolled patients responded to the medication (partial or complete response). Data from these studies revealed that patients with CTCL received Romidepsin injections showed durable clinical responses regardless of disease stage. In addition, patients with pruritus may experience benefit from Romidepsin even in the absence of a clinical response (Reddy 2016). In 2011, U.S. FDA approved a new indication for Romidepsin; treatment of peripheral T-cell lymphoma in patients who had received at least one prior therapy (U.S. Food and Drug Administration 2010). This HDAC inhibitor acts as a prodrug; its disulfide bond reduction and subsequent interaction of free thiol residue with the active site of class I and II HDAC enzymes in the cell can lead to enzyme inhibition and further cell cycle arrest and apoptosis-related gene activation. Without regard to its HDAC inhibitory nature, Romidepsin can also reverse the effect of Ras oncogene and this could be another antitumor mechanism of Romidepsin (Vander Molen et al. 2011). Considering the immune dysregulation in CTCL, an in vitro analysis conducted on the immunomodulatory effect of Romidepsin and Vorinostat in this disease. Results of the study showed that both medications strikingly restrain immunosuppressive cytokine, interleukin 10 (IL-10), which is frequently overexpressed in CTCL, at the RNA and protein level in CTCL cell lines. In this context, immonomodulation might be associated with clinical activity of these medications in CTCL (Tiffon et al. 2011).

\section{Belinostat (Beleodaq ${ }^{\mathrm{TM}}$ )}

Belinostat (Beleodaq ${ }^{\mathrm{TM}}$ ) is another HDACi with similar pharmacological effect to Vorinostat indicated for the treatment of patients with relapsed or refractory peripheral T-cell lymphoma (PTCL). This indication was approved by U.S. FDA in 2014 under accelerated approval based on tumour response rate and duration of response (Lee et al. 2015). The pivotal study was a phase II multicenter open-labeled clinical trial in which $25.8 \%$ of enrolled patients showed overall response to Belinostat. The median duration of response based on the first date of response to disease progression or death was 8.4 months and $7.5 \%$ of patients were able to receive a stem cell transplant after treatment with Belinostat (O'Connor et al. 2015). Safety profile and clinical efficacy of oral Belinostat which was investigated in a phase I clinical study indicated that oral Belinostat was well tolerated and $42.8 \%$ of assessed patients showed stable disease. In this regard, Belinostat can be considered as the only HDACi which has multiple potential routes of administration, including IV bolus, IV infusion, and oral administration (Sawas et al. 2015).

\section{Chidamide (Epidaza ${ }^{\mathrm{TM}}$ )}

Another marketed HDACi medication for treatment of relapsed or refractory PTCL is Chidamide (Tucidinostat) which was approved by CFDA in 2014 under the trade name of Epidaza ${ }^{\mathrm{TM}}$. Results of its pivotal phase II clinical trial showed that $28 \%$ of PTCL-enrolled patients had overall responses to oral Chidamide (Shi et al. 2015). There are also several ongoing preliminary clinical trials evaluating the efficacy of Chidamide in cutaneous T-cell lymphoma, adult T-cell leukemia-lymphoma, and solid tumors (Dong et al. 2012). Chidamide makes cell cycle arrest and apoptosis via inhibition of HDAC1, HDAC2, HDAC3, and HDAC10. Chidamide also seems to induce tumour specific antigen and antigen-specific T-cell cytotoxicity, augmentation of NK cell antitumour activity, promoting cancerous stem cell differentiation, and resensitization of resistant tumour cells to medicines such as taxanes, platinums, and topoisomerase II inhibitors (Gong et al. 2012; Ning et al. 2012).

\section{Panobinostat (Farydak ${ }^{\mathrm{TM}}$ )}

Panobinostat (Farydak ${ }^{\mathrm{TM}}$ ) is the latest HDAC inhibitor which in combination with Bortezomib and Dexamethasone was approved by U.S. FDA in 2015. It is indicated for management of multiple myeloma patients who have received at least two prior regimens, including Bortezomib and an immunomodulatory agent (Simon 2015). Like Vorinostat and Belinostat, Panobinostat is a pan-HDAC inhibitor which possesses superior antitumour potency in terms of inhibition of cancer cell proliferation and viability (Atadja 2009). Results from the pivotal phase III clinical trial of the efficacy and safety of Panobinostat-Bortezomib-Dexamthasone combinational regimen indicated that median progressionfree survival in patients who received Panobinostat was approximately 1.5 fold greater than that of placebo and also significantly higher proportion of patients showed complete response in Panobinostat group (San-Miguel et al. 2014). In another phase III clinical study, the impact of duration of treatment with Panobinostat-Bortezomib-Dexamethasone on efficacy and safety of the regimen was evaluated. The results revealed that prolonged treatment with this combinational regimen can increase progression-free survival (PFS) and the severity of the regimen adverse effects subsided during treatment protocols in which administration of Bortezomib and Dexamethasone was reduced per protocol (San-Miguel et al. 2015). Despite these advantages, Panobinostat has not been successful in overall survival improvement (San-Miguel et al. 2016).

Preclinical and some clinical studies have demonstrated that combinations of HDACi with DNMT inhibitors have synergistic effects in treatment of hematopoietic malignancies, although the exact mechanism of these effects requires 
further investigations (Garcia-Manero et al. 2011; Nieto et al. 2016; Odenike et al. 2008; Raha 2016; Rozati et al. 2016).

Despite all the clinical benefits in hematopoietic malignancies, epigenetic medications have failed to exhibit a plausible antineoplastic activity in solid tumors. More recently with a new strategy towards targeting epigenetic regulatory mutations, the second generation of epigenetic medications has shown encouraging results in clinical trials. Examples of such investigational medications can be inhibitors of histone methyltransferases (HMTi) DOTIL and EZH2 (enhancer of zeste homolog 2) (Campbell and Tummino 2014). Interestingly, some approved medications in cardiovascular or psychology disorders including Tranylcypromine, Valproate sodium, Hydralazine, and Procainamide have been found to interact with epigenetic machinery and thus can be promising candidates for treatment of epigenetic diseases such as cancer (Cervera et al. 2012; Morera et al. 2016; Pfister and Ashworth 2017).
For the time being, miRNA-based therapeutics are undergoing clinical trials, but have not yet entered the market. It is expected to have more developments in the miRNA-based therapeutics in both epigenetic and gene therapy approaches in the near future (Table 3).

Based on clinical outcomes, the current epigenetic medications can be beneficial to some patients with certain situations. Hypomethylating agents (Azacitidine and Decitabine) can be considered as the most suitable therapeutic options in elderly AML patients who are not eligible for intensive chemotherapy regimens. They can induce remissions and potentially prolong survival in some older patients with newly diagnosed AML or advanced MDS. Although there is no clinical study that directly compares the efficacy of Azacitidine and Decitabine, some physicians may prefer Azacitidine due to its ease of subcutaneous administration in outpatient cases, while others prefer Decitabine because of shorter duration of therapy. In cutaneous T-cell lymphoma, histone deacetylase inhibitors have shown

Table 3 Epigenetic medications in the pharmaceutical market

\begin{tabular}{|c|c|c|c|c|c|}
\hline Medication name & Year of approval & Indication & Dose schedule & Common adverse reactions & References \\
\hline Azacitidine (Vidaza TM) & 2004 & MDS & $\begin{array}{l}\text { Initial } 2 \text { cycles: } 75 \mathrm{mg} / \\
\mathrm{m}^{2} \mathrm{SC} \text { injection or IV } \\
\text { infusion once daily for } \\
\text { 1-week and } 2 \text {-week } \\
\text { intervals, } 100 \mathrm{mg} / \mathrm{m}^{2} \text { in } \\
\text { subsequent } 4-6 \text { cycles }\end{array}$ & $\begin{array}{l}\text { Myelosuppression, GI } \\
\text { discomfort, pyrexia }\end{array}$ & Kaminskas et al. (2005a) \\
\hline Decitabine (Dacogen ${ }^{\mathrm{TM}}$ ) & 2006 & MDS & $\begin{array}{l}\text { Regimen } 1 \text { : IV infusion of } \\
15 \mathrm{mg} / \mathrm{m}^{2} \mathrm{TDS} \text { for } 3 \text { days } \\
\text { in cycles with } 6 \text {-week } \\
\text { intervals } \\
\text { Regimen } 2 \text { : IV infusion } \\
\text { of } 20 \mathrm{mg} / \mathrm{m}^{2} \text { once daily } \\
\text { for } 5 \text { days in cycles with } \\
\text { 6-week intervals }\end{array}$ & $\begin{array}{l}\text { Myelosuppression, GI } \\
\text { discomfort, pyrexia }\end{array}$ & Wijermans et al. (2005) \\
\hline Vorinostat (Zolinza TM) & 2006 & CTCL & $400 \mathrm{mg}$ PO once daily & $\begin{array}{l}\text { Thrombocytopenia, ane- } \\
\text { mia pulmonary embo- } \\
\text { lism, GI discomfort }\end{array}$ & Mann et al. (2007) \\
\hline Romidepsin (Istodax ${ }^{\mathrm{TM}}$ ) & $\begin{array}{l}2009 \\
2011\end{array}$ & $\begin{array}{l}\text { CTCL } \\
\text { PTCL }\end{array}$ & $\begin{array}{l}\text { IV infusion of } 14 \mathrm{mg} / \mathrm{m}^{2} \\
\text { once weekly for } 3 \text { weeks } \\
\text { in cycles with } 4 \text {-week } \\
\text { intervals }\end{array}$ & $\begin{array}{l}\text { Thrombocytopenia, ane- } \\
\text { mia, nausea }\end{array}$ & $\begin{array}{l}\text { Reddy (2016), U.S. Food } \\
\text { and Drug Administra- } \\
\text { tion (2010) }\end{array}$ \\
\hline Belinostat (Beleodaq ${ }^{\mathrm{TM}}$ ) & 2014 & PTCL & $\begin{array}{l}\text { IV infusion of } 1000 \mathrm{mg} / \mathrm{m}^{2} \\
\text { once daily on days } 1-5 \\
\text { in cycles with } 3 \text {-week } \\
\text { intervals }\end{array}$ & $\begin{array}{l}\text { Thrombocytopenia, } \\
\text { anemia, GI discomfort, } \\
\text { pyrexia }\end{array}$ & Lee et al. (2015) \\
\hline Chidamide (Epidaza ${ }^{\mathrm{TM}}$ ) & 2014 & PTCL & $30 \mathrm{mg}$ PO twice a week & $\begin{array}{l}\text { Thrombocytopenia, leuko- } \\
\text { penia and neutropenia }\end{array}$ & Shi et al. (2015) \\
\hline Panobinostat (Faryadak ${ }^{\mathrm{TM}}$ ) & 2015 & MM & $\begin{array}{l}\text { PO of } 20 \text { mgQID for } \\
2 \text { weeks in cycles with } \\
\text { 3-week intervals for } 8 \\
\text { cycles }\end{array}$ & $\begin{array}{l}\text { Thrombocytopenia, lym- } \\
\text { phopenia, leukopenia, } \\
\text { neutropenia, anemia, } \\
\text { severe diarrhea, pyrexia, } \\
\text { cardiac ischemic events }\end{array}$ & San-Miguel et al. (2014) \\
\hline
\end{tabular}

$M D S$ myelodysplastic syndrome, $S C$ subcutaneous, $I V$ intravenous, $T D S$ every $8 \mathrm{~h}, C T C L$ cutaneous T-cell lymphoma, $P O$ oral administration, $P T C L$ peripheral T-cell lymphoma, $M M$ multiple myeloma, $Q I D$ every other day 
Table 4 Efficacy of common cancer treatments and new therapeutic options in cancers associated with SM

\begin{tabular}{|c|c|c|c|}
\hline Cancer & Treatment & Response & References \\
\hline \multirow[t]{4}{*}{ HNSCC } & Cisplatin + RT & $\begin{array}{l}\text { 2- and 5-year OSR: } 74 \text { and } 54 \% \text { for Cispl- } \\
\text { atin + RT; } 75 \text { and } 56 \% \text { for RT } \\
\text { 2- and 5-year DFS: } 61 \% \text { and } 36 \% \text { for Cispl- } \\
\text { atin + RT; } 44 \text { and } 27 \% \text { for RT }\end{array}$ & Forastiere et al. (2003) \\
\hline & Carboplatin + RT & $\begin{array}{l}\text { 5-year OSR: } 22 \% \text { Carboplatin + RT vs. } 16 \% \text { RT } \\
\text { 5-year DFS: } 27 \% \text { Carboplatin + RT vs. } 15 \% \text { RT }\end{array}$ & Denis et al. (2004) \\
\hline & Gendicine + RT & $\begin{array}{l}\text { PR: } 29 \% \text { Gendicine + RT vs. } 19 \% \text { RT } \\
\text { CR: } 64 \% \text { Gendicine + RT vs. } 60 \% \text { RT }\end{array}$ & Ma et al. (2008) \\
\hline & Oncorine + Cisplatin + Fluorouracil & ORR: 78.8 vs. $39.6 \%$ control & Xia et al. (2004) \\
\hline \multirow[t]{4}{*}{ Lung cancer } & Necitumumab + Gemcitabine + Cisplatin & $\begin{array}{l}\text { Median survival time: } 11.5 \mathrm{~m}(9.9 \mathrm{~m} \text { with Gem- } \\
\text { citabine + Cisplatin) }\end{array}$ & Thatcher et al. (2015) \\
\hline & Docetaxel + Carboplatin & $\begin{array}{l}\text { Median survival time: } 11.3 \mathrm{~m} \\
\text { 2-year OSR: } 21 \% \\
\text { ORR: } 31.6 \%\end{array}$ & Fossella et al. (2003) \\
\hline & Gendicine & $\begin{array}{l}\text { SD rate: } 46.7 \% \\
\text { PR: } 33.3 \%\end{array}$ & Zhang and Lu (2012) \\
\hline & Cimavax-EGF & Median survival time: $12.43 \mathrm{~m}$ & Rodriguez et al. (2016) \\
\hline \multirow[t]{5}{*}{ Melanoma } & Nivolumab + Ipilimumab & $\begin{array}{l}\text { PFS: } 11.5 \mathrm{~m} \text { with Nivolumab plus Ipilimumab, } \\
2.9 \text { m with Ipilimumab and } 6.9 \mathrm{~m} \text { with } \\
\text { Nivolumab }\end{array}$ & Larkin et al. (2015) \\
\hline & Dacarbazine & $\begin{array}{l}\text { CR: } 5 \% \\
\text { ORR: } 20 \% \\
\text { Median response duration: } 5-6 \mathrm{~m}\end{array}$ & Serrone et al. (2000) \\
\hline & Fotemustine & $\begin{array}{l}\text { OSR: } 15.2 \% \text { (vs. } 6.8 \% \text { Dacarbazine) } \\
\text { Median response duration: } 5.8 \mathrm{~m}\end{array}$ & Avril et al. (2004) \\
\hline & Rigvir & $\begin{array}{l}\text { Risk of death was } 4.39-6.57 \text {-fold lower in } \\
\text { patients received Rigvir after surgical excision } \\
\text { in comparison with control group }\end{array}$ & Doniņa et al. 2015 \\
\hline & T-VEC & $\begin{array}{l}\text { Median OS: } 23.3 \text { m with T-VEC ( } 18.9 \text { m with } \\
\text { GM-CSF alone) ORR: } 26 \% \text { with T-VEC }(6 \% \\
\text { with GM-CSF alone) } \\
\text { CR: } 10.8 \% \text { with T-VEC ( } 1 \% \text { with GM-CSF } \\
\text { alone) } \\
\text { DRR: } 16 \% \text { with T-VEC ( } 2 \% \text { with GM-CSF } \\
\text { alone) }\end{array}$ & Kaufman and Bines (2010) \\
\hline \multirow[t]{2}{*}{ Prostate cancer } & Docetaxel + Prednisone & $\begin{array}{l}\text { Median survival time: } 19.2 \mathrm{~m} \\
\text { 3-year OSR: } 18.6 \%\end{array}$ & Berthold et al. (2008) \\
\hline & Sipuleucel-T & OS: $25.9 \mathrm{~m}$ & Small et al. 2006 \\
\hline \multirow[t]{3}{*}{ AML } & Cytarabine + Daunorubicin & $\begin{array}{l}\text { ORR: } 62 \% \\
\text { 5-year OSR: } 12 \%\end{array}$ & Burnett et al. (2009) \\
\hline & Azacitidine & $\begin{array}{l}\text { OS: } 14.2 \mathrm{~m} \\
\text { 1-year OS: } 46.5 \%\end{array}$ & Dombret et al. (2015) \\
\hline & Decitabine & CR and nCR: $17.8 \%$ & Kantarjian et al. (2012) \\
\hline \multirow[t]{3}{*}{ CTCL } & $\begin{array}{l}\mathrm{ECP}+ \\
\text { immunomodulatory agents (interferons, reti- } \\
\text { noids) }\end{array}$ & $\begin{array}{l}\text { ORR: } 84 \% \text { ( } 75 \% \text { with ECP alone) } \\
\text { Median survival time: } 74 \mathrm{~m}(66 \mathrm{~m} \text { with ECP } \\
\text { alone) }\end{array}$ & Suchin et al. (2002) \\
\hline & Vorinostat & PR: $30 \%$ & Mann et al. (2007) \\
\hline & Romisdepsin & ORR: $34 \%$ & \\
\hline \multirow[t]{3}{*}{ PTCL } & CHOP & 3-year OSR: $41.1 \%$ & Schmitz et al. (2010) \\
\hline & Belinostat & $\begin{array}{l}\text { ORR: } 25.8 \% \\
\text { Median duration of response: } 8.4 \mathrm{~m}\end{array}$ & O’Connor et al. (2015) \\
\hline & Chidamide & ORR: $28 \%$ & Shi et al. 2015 \\
\hline
\end{tabular}


Table 4 (continued)

\begin{tabular}{|c|c|c|c|}
\hline Cancer & Treatment & Response & References \\
\hline \multirow[t]{3}{*}{$M M$} & Lenaliomide + Dexamethasone & $\begin{array}{l}\text { ORR: } 79 \% \text { (with high-dose dexamethasone) vs. } \\
68.3 \% \text { (low-dose dexamethasone) }\end{array}$ & Rajkumar et al. (2010) \\
\hline & Bortezomib & $\begin{array}{l}\text { ORR: } 41 \% \\
\text { Median duration of response: } 8.4 \mathrm{~m} \\
\text { PFS: } 17.3 \mathrm{~m}\end{array}$ & Richardson et al. (2009) \\
\hline & $\begin{array}{l}\text { Panobinostat }+ \text { Bortezomib + Dexamethasone } \\
\text { (refractory cases) }\end{array}$ & $\begin{array}{l}\text { PFS: } 11.99 \mathrm{~m}(8.08 \mathrm{~m} \text { with placebo }) \\
\text { ORR: } 27.6 \% \text { (15.7\% with placebo) } \\
\text { Median duration of response: } 13.4 \mathrm{~m}(10.87 \mathrm{~m} \\
\text { with placebo) }\end{array}$ & San-Miguel et al. (2014) \\
\hline
\end{tabular}

$H N S C C$ head and neck squamous-cell carcinoma, $R T$ radiotherapy, $O S R$ overall survival rate, $D F S$ disease-free survival, $O R R$ overall response rate, $P R$ partial response, $C R$ complete response, $S D$ stable disease, $P F S$ progression-free survival, $G M$-CSF granulocyte-macrophage colonystimulating factor, $A M L$ acute myeloid leukemia, $D R R$ durable response rate, $C R$ plus $n C R$ complete response rate plus near complete response rate, $C T C L$ cutaneous T-cell lymphoma, ECP extracorporeal photopheresis, $P T C L$ peripheral T-cell lymphoma, $C H O P$ Cyclophosphamide-Doxorubicin-Vincristine-Prednisone, $M M$ multiple myeloma

outstanding results and approximately one-third of patients experienced partial or complete remission after treatment with these agents. Vorinostat and Romidepsin are the two potent HDAC inhibitors, which result in significant improvements on the cutaneous manifestations such as pruritus in CTCL patients. Acceptable safety profile and available oral and injectable dosage forms make them appropriate alternatives to the conventional therapies. Moreover, Romidepsin with its prodrug nature seems to have a more convenient safety profile. However, these medications did not prolong the overall survival and this could be regarded as their major drawback. Histone deacetylase inhibitors approved for treatment of PTCL (Romidepsin, Belinostat, and Chidamide) would be better reserved for refractory conditions. In this regard, Belinostat with multiple routes of administration (PO, IV infusion, and IV bolus), tolerable adverse effects, and encouraging improvement in the patient's quality of life can be highly recommended as the best second-line treatment option for PTCL. The last approved epigenetic medication Panobinostat is indicated for treatment of multiple myeloma in a combinational regimen with Bortezomib and Dexamethasone. Clinical data showed that patients receiving this regimen experienced significantly higher progressionfree survival but not overall survival. Moreover, the small therapeutic window makes it less suitable therapeutic option for multiple myeloma (Table 4).

\section{Conclusion}

The use of SM as a warfare agent over the past few decades has left many detrimental effects in thousands of people. Treatment of its long-term adverse events is still one of the pervasive healthcare problems. Cancer as the most serious consequence of SM intoxication should be regarded as the first priority in medical management of SM complications.
Currently, the most feasible cancer therapy approaches are limited to chemotherapy and radiotherapy. Although the development of new strategies such as immunotherapy has been strikingly successful, there is still tangible need to explore novel therapies to enhance the efficacy of treatment regimens by targeting malignant cells through different mechanisms. Considering the origin of the cancer, genetic and epigenetic therapies have been efficiently used to target defective genes or gene regulation systems. In contrast to the conventional therapies, these strategies can specifically affect the tumor cells and have minimal effect on normal cells. Hence, they can provide a better quality of life for patients. Presently available medications with genetic and epigenetic mechanisms of action can improve the chance of complete remission in some types of malignancies including squamous-cell carcinoma, melanoma, lung, prostate, and hematopoietic cancers. Noteworthy, SM-exposed individuals are at a significantly higher risk of developing these kinds of cancers. Therefore, genetic and epigenetic cancer treatments including Gendicine, Imlygic, Provenge, CimavaxEGF, Azacitidine, Vorinostat, Romidepsin, and Belinostat will yield outstanding benefits for SM-exposed patients suffering from cancer.

\section{References}

Akao Y, Nakagawa Y, Naoe T (2006) MicroRNAs 143 and 145 are possible common onco-microRNAs in human cancers. Oncol Rep 16:845-850

Alberts P, Olmane E, Brokāne L, Krastiņa Z, Romanovska M et al (2016) Long-term treatment with the oncolytic ECHO-7 virus Rigvir of a melanoma stage IV M1c patient, a small cell lung cancer stage IIIA patient, and a histiocytic sarcoma stage IV patient-three case reports. APMIS 124:896-904

Amira A, Berredjem M, Aouf N-E (2015) Synthesis of novel nitrogen mustards containing amino alcohol derivatives. JOLST 3:65-68 
Ananthaswamy HN, Loughlin SM, Cox P, Evans RL, Ullrich SE, Kripke ML (1997) Sunlight and skin cancer: inhibition of p53 mutations in UV-irradiated mouse skin by sunscreens. Nat Med 3:510-514

Andtbacka RH, Collichio FA, Amatruda T, Senzer N, Chesney J et al (2014) Final planned overall survival (OS) from OPTiM, a randomized Phase III trial of talimogene laherparepvec (T-VEC) versus GM-CSF for the treatment of unresected stage IIIB/C/ IV melanoma (NCT00769704). J Immunother Cancer 2:P263

Apuri S, Al Ali N, Padron E, Lancet JE, List AF, Komrokji RS (2017) Evidence for selective benefit of sequential treatment with hypomethylating agents in patients with myelodysplastic syndrome. Clin Lymphoma Myeloma Leuk 17:211-214

Arnouk H (2012) Advancements in tumor immunotherapy and cancer vaccines. InTech

Atadja P (2009) Development of the pan-DAC inhibitor panobinostat (LBH589): successes and challenges. Cancer Lett 280:233-241

Avril M, Aamdal S, Grob J et al (2004) Fotemustine compared with dacarbazine in patients with disseminated malignant melanoma: a phase III study. J Clin Oncol 22(6):1118-1125

Babiker HM, Riaz IB, Husnain M, Borad MJ (2017) Oncolytic virotherapy including Rigvir and standard therapies in malignant melanoma. Oncolytic Virother 6:11-18

Balali-Mood M (2015) Early and delayed effects of sulfur mustard in Iranian veterans after the Iraq-Iran conflict. In: Gupta RC (ed) Handbook of toxicology of chemical warfare agents, 2nd edn, Chap 5. Academic Press, Boston, pp 37-46

Banerjee J, Chan YC, Sen CK (2011) MicroRNAs in skin and wound healing. Physiol Genomics 43:543-556

Batal M, Boudry I, Mouret S, Cléry-Barraud C, Wartelle J et al (2014) DNA damage in internal organs after cutaneous exposure to sulphur mustard. Toxicol Appl Pharmacol 278:39-44

Beedanagari S, Vulimiri SV, Bhatia S, Mahadevan B (2014) Chapter 43-genotoxicity biomarkers: molecular basis of genetic variability and susceptibility A2-Gupta, Ramesh C. Biomarkers in toxicology: 729-42. Academic, Boston, pp 729-742

Beer TM, Bernstein GT, Corman JM, Glode LM, Hall SJ et al (2011) Randomized trial of autologous cellular immunotherapy with Sipuleucel-T in androgen-dependent prostate cancer. Clin Cancer Res 17:4558-4567

Behravan E, Moallem SA, Khateri S, Maraghi E, Jowsey P et al (2013) Deoxyribonucleic acid damage in Iranian veterans 25 years after wartime exposure to sulfur mustard. J Res Med Sci 18:239-244

Bell JC, Lichty B, Stojdl D (2003) Getting oncolytic virus therapies off the ground. Cancer Cell 4:7-11

Bennett JM, Catovsky D, Daniel MT, Flandrin G, Galton DAG et al (1982) Proposals for the classification of the myelodysplastic syndromes. Br J Haematol 51:189-199

Berthold DR, Pond GR, Soban F, Wit Rd, Eisenberger M, Tannock IF (2008) Docetaxel plus prednisone or mitoxantrone plus prednisone for advanced prostate cancer: updated survival in the TAX 327 study. J Clin Oncol 26(2):242-245

Biswas S, Rao CM (2017) Epigenetics in cancer: fundamentals and beyond. Pharmacol Ther 173:118-134

Bodner SM, Minna JD, Jensen SM, D’Amico D, Carbone D et al (1992) Expression of mutant p53 proteins in lung cancer correlates with the class of p53 gene mutation. Oncogene 7:743-749

Borak J, Sidell FR (1992) Agents of chemical warfare: sulfur mustard. Ann Emerg Med 21:303-308

Bressy C, Hastie E, Grdzelishvili VZ (2017) Combining oncolytic virotherapy with $\mathrm{p} 53$ tumor suppressor gene therapy. Mol Ther Oncolytics 5:20-40

Bruvere R, Feldmane G, Ferdats A, Heisele O, Muceniece A (2006) Adjuvant immunotheraphy with virus-mediated biomodulators developed in Latvia: experimental and clinical data. Melanoma Res 16:S33-S34
Burnett AK, Milligan D, Goldstone A et al (2009) The impact of dose escalation and resistance modulation in older patients with acute myeloid leukaemia and high risk myelodysplastic syndrome: the results of the LRF AML14 trial. Br J Haematol 145(3):318-332

Campbell RM, Tummino PJ (2014) Cancer epigenetics drug discovery and development: the challenge of hitting the mark. J Clin Invest. 124:64-69

Ceccacci E, Minucci S (2016) Inhibition of histone deacetylases in cancer therapy: lessons from leukaemia. Br J Cancer 114:605-611

Cervera E, Candelaria M, López-Navarro O, Labardini J, GonzalezFierro A et al (2012) Epigenetic therapy with hydralazine and magnesium valproate reverses imatinib resistance in patients with chronic myeloid leukemia. Clin Lymphoma Myeloma Leuk 12:207-212

Chaisaingmongkol J, Popanda O, Warta R, Dyckhoff G, Herpel E et al (2012) Epigenetic screen of human DNA repair genes identifies aberrant promoter methylation of NEIL1 in head and neck squamous cell carcinoma. Oncogene 31:5108-5116

Chang X, Sun Y, Han S, Zhu W, Zhang H, Lian S (2015) MiR-203 inhibits melanoma invasive and proliferative abilities by targeting the polycomb group gene BMI1. Biochem Biophys Res Commun 456:361-366

Chappell G, Pogribny IP, Guyton KZ, Rusyn I (2016) Epigenetic alterations induced by genotoxic occupational and environmental human chemical carcinogens: a systematic literature review. Mutat Res Rev Mutat Res 768:27-45

Chen H-Y, Han Z-B, Fan J-W, Xia J, Wu J-Y et al (2012) miR-203 expression predicts outcome after liver transplantation for hepatocellular carcinoma in cirrhotic liver. Med Oncol 29:1859-1865

Chiam K, Ricciardelli C, Bianco-Miotto T (2014) Epigenetic biomarkers in prostate cancer: current and future uses. Cancer Lett 342:248-256

Christakis P (2011) The birth of chemotherapy at Yale: bicentennial lecture series: surgery grand round. Yale J Biol Med. 84:169-172

Cogle CR, Scott BL, Boyd T, Garcia-Manero G (2015) Oral Azacitidine (CC-486) for the treatment of myelodysplastic syndromes and acute myeloid leukemia. Oncologist 20:1404-1412

Cross D, Burmester JK (2006) Gene therapy for cancer treatment: past, present and future. Clin Med Res 4:218-227

de Ilarduya CT, Sun Y, Düzgüneş N (2010) Gene delivery by lipoplexes and polyplexes. Eur J Pharm Sci 40:159-170

de Unamuno B, Palanca S, Botella R (2015) Update on melanoma epigenetics. Curr Opin Oncol 27:420-426

Denis F, Garaud P, Bardet E et al (2004) Final results of the 94-01 French Head and Neck Oncology and Radiotherapy Group randomized trial comparing radiotherapy alone with concomitant radiochemotherapy in advanced-stage oropharynx carcinoma. J Clin Oncol 22(1):69-76

Deppe J, Steinritz D, Santovito D, Egea V, Schmidt A et al (2016) Upregulation of miR-203 and miR-210 affect growth and differentiation of keratinocytes after exposure to sulfur mustard in normoxia and hypoxia. Toxicol Lett 244:81-87

Diesch J, Zwick A, Garz A-K, Palau A, Buschbeck M, Götze KS (2016) A clinical-molecular update on azanucleoside-based therapy for the treatment of hematologic cancers. Clin Epigenetics 8:71

Dimopoulos M, Siegel DS, Lonial S, Qi J, Hajek R et al (2013) Vorinostat or placebo in combination with bortezomib in patients with multiple myeloma (VANTAGE 088): a multicentre, randomised, double-blind study. Lancet Oncol 14:1129-1140

Doepker MP, Zager JS (2016) An update on talimogene laherparepvec. Am J Hematol Oncol ${ }^{\circledR}$ 12:17-20

Dombret H, Seymour JF, Butrym A, Wierzbowska A, Selleslag D et al (2015) International phase 3 study of azacitidine vs conventional care regimens in older patients with newly diagnosed AML with > 30\% blasts. Blood 126:291-299 
Dong M, Ning Z-Q, Xing P-Y, Xu J-L, Cao H-X et al (2012) Phase I study of chidamide (CS055/HBI-8000), a new histone deacetylase inhibitor, in patients with advanced solid tumors and lymphomas. Cancer Chemother Pharmacol 69:1413-1422

Doniṇa S, Strēle I, Proboka G, Auziṇš J, Alberts P et al (2015) Adapted ECHO-7 virus Rigvir immunotherapy (oncolytic virotherapy) prolongs survival in melanoma patients after surgical excision of the tumour in a retrospective study. Melanoma Res $25: 421-426$

dos Santos Guimarães I et al (2013) Conventional cancer treatment, cancer treatment - conventional and innovative approaches. Rangel L (ed) InTech, pp 3-35

Durrant LG, Scholefield JH (2009) Principles of cancer treatment by immunotherapy. Surgery (Oxford) 27:161-164

Duvic M, Vu J (2007) Update on the treatment of cutaneous T-cell lymphoma (CTCL): focus on vorinostat. Biologics 1:377-392

Easton D, Peto J, Doll R (1988) Cancers of the respiratory tract in mustard gas workers. Br J Ind Med 45:652-659

Elwood JM, Koh HK (1994) Etiology, epidemiology, risk factors, and public health issues of melanoma. Curr Opin Oncol 6:179

Emadi S, Mortazavi M, Mortazavi H (2008) Late cutaneous manifestations 14 to 20 years after wartime exposure to sulfur mustard gas: a long-term investigation. Arch Dermatol 144:1059-1061

European Medicines Agency (2008) Vidaza, EMEA/H/C/000978. http://www.ema.europa.eu/docs/en_GB/document_library/ Summary_of_opinion_-_Initial_authorisation/human/000978/ WC500059523.pdf. Accessed 23 Oct 2008

European Medicines Agency (2009) Withdrawal Assessment Report for Contusugene Ladenovec, Procedure No. EMEA/H/C/1041. http://www.ema.europa.eu/docs/en_GB/document_library/Application_withdrawal_assessment_report/2010/01/WC500060811. pdf. Accessed 2009

European Medicines Agency (2012) Dacogen, EMEA/461407/2012. 2012. http://www.ema.europa.eu/docs/en_GB/document_library/ Summary_of_opinion_-_Initial_authorisation/human/002221/ WC500130136.pdf. Accessed 19 Jul 2012

Falk S (2009) Principles of cancer treatment by radiotherapy. Surgery (Oxford) 27:169-172

Farkas A, Conrad C, Tonel G, Borbenyi Z, Kemeny L et al (2006) Current state and perspectives of dendritic cell vaccination in cancer immunotherapy. Skin Pharmacol Physiol 19:124-131

Forastiere AA, Goepfert H, Maor M et al (2003) Concurrent chemotherapy and radiotherapy for organ preservation in advanced laryngeal cancer. N Engl J Med 349(22):2091-2098

Fossella F, Pereira JR, von Pawel J et al (2003) Randomized, multinational, phase III study of docetaxel plus platinum combinations versus vinorelbine plus cisplatin for advanced nonsmall-cell lung cancer: the TAX 326 study group. J Clin Oncol 21(16):3016-3024

Garcia-Manero G, Estey EH, Jabbour E, Borthakur G, Kadia T et al (2011) Final report of a phase II study of 5-azacitidine and vorinostat in patients (pts) with newly diagnosed myelodysplastic syndrome (MDS) or acute myelogenous leukemia (AML) not eligible for clinical trials because poor performance and presence of other comorbidities. Blood 118:608

Ghabili K, Agutter PS, Ghanei M, Ansarin K, Shoja MM (2010) Mustard gas toxicity: the acute and chronic pathological effects. J Appl Toxicol 30:627-643

Ghanei M, Vosoghi AA (2002) An epidemiologic study to screen for chronic myelocytic leukemia in war victims exposed to mustard gas. Environ Health Perspect 110:519

Ghobadi A, Choi J, Fiala MA, Fletcher T, Liu J et al (2016) Phase I study of azacitidine following donor lymphocyte infusion for relapsed acute myeloid leukemia post allogeneic stem cell transplantation. Leuk Res 49:1-6
Ginn SL, Alexander IE, Edelstein ML, Abedi MR, Wixon J (2013) Gene therapy clinical trials worldwide to 2012-an update. J Gene Med 15:65-77

Giorgio C, Dell'Aversana C, Altucci L (2016) Chapter 27-epigenetics in acute myeloid leukemia A2-Tollefsbol, T.O. Medical epigenetics: 483-98. Academic, Boston, pp 483-498

Gong K, Xie J, Yi H, Li W et al (2012) CS055 (Chidamide/HBI-8000), a novel histone deacetylase inhibitor, induces G1 arrest, ROSdependent apoptosis and differentiation in human leukaemia cells. Biochem J 443:735-746

Goodyear O, Agathanggelou A, Novitzky-Basso I, Siddique S, McSkeane $\mathrm{T}$ et al (2010) Induction of a CD8 + T-cell response to the MAGE cancer testis antigen by combined treatment with azacitidine and sodium valproate in patients with acute myeloid leukemia and myelodysplasia. Blood 116:1908-1918

Grant S, Easley C, Kirkpatrick P (2007) Vorinostat. Nat Rev Drug Discov 6:21-22

Greig SL (2016) Talimogene laherparepvec: first global approval. Drugs 76(1):147-154

Greither T, Grochola LF, Udelnow A, Lautenschläger C, Würl P, Taubert H (2010) Elevated expression of microRNAs 155, 203, 210 and 222 in pancreatic tumors is associated with poorer survival. Int J Cancer 126:73-80

Guo J, Xin H (2006) Splicing out the West? Science 314(5803):1232-1235

Higano CS, Schellhammer PF, Small EJ, Burch PA, Nemunaitis J et al (2009) Integrated data from 2 randomized, double-blind, placebo-controlled, phase 3 trials of active cellular immunotherapy with Sipuleucel-T in advanced prostate cancer. Cancer 115:3670-3679

Hodjat M, Rahmani S, Niaz K, Navaei-Nigjeh M et al (2017) Environmental toxicants, incidence of degenerative diseases, and therapies from the epigenetic point of view. Arch Toxicol 91:2577-2597

Hollenbach PW, Nguyen AN, Brady H, Williams M, Ning Y et al (2010) A comparison of azacitidine and decitabine activities in acute myeloid leukemia cell lines. PLoS One 5:e9001

Hosseini-khalili A, Haines DD, Modirian E, Soroush M, Khateri S et al (2009) Mustard gas exposure and carcinogenesis of lung. Mutat Res 678:1-14

Hughes B (2010) 2009 FDA drug approvals. Nat Rev Drug Discov 9:89-92

Hunter P (2015) The second coming of epigenetic drugs: a more strategic and broader research framework could boost the development of new drugs to modify epigenetic factors and gene expression. EMBO Rep 16:276-279

Ibraheem D, Elaissari A, Fessi H (2014) Gene therapy and DNA delivery systems. Int J Pharm 459:70-83

Imani S, Panahi Y, Salimian J, Fu J, Ghanei M (2015) Epigenetic: a missing paradigm in cellular and molecular pathways of sulfur mustard lung: a prospective and comparative study. Iran J Basic Med Sci 18:723-736

Issa J-PJ, Kantarjian HM, Kirkpatrick P (2005) Azacitidine. Nat Rev Drug Discov. 4:275-276

Janssen MJ, Arcolino FO, Schoor P, Kok RJ, Mastrobattista E (2016) Gene based therapies for kidney regeneration. Eur J Pharmacol 790:99-108

Johnson DB, Puzanov I, Kelley MC (2015) Talimogene laherparepvec (T-VEC) for the treatment of advanced melanoma. Immunotherapy 7:611-619

Kaminskas E, Farrell A, Abraham S, Baird A, Hsieh L-S et al (2005a) Approval summary: azacitidine for treatment of myelodysplastic syndrome subtypes. Clin Cancer Res 11:3604-3608

Kaminskas E, Farrell AT, Wang Y-C, Sridhara R, Pazdur R (2005b) FDA drug approval summary: azacitidine (5-azacytidine, Vid$\mathrm{aza}^{\mathrm{TM}}$ ) for injectable suspension. Oncologist 10:176-182 
Kantarjian HM, Thomas XG, Dmoszynska A, Wierzbowska A, Mazur $\mathrm{G}$ et al (2012) Multicenter, randomized, open-label, phase III trial of decitabine versus patient choice, with physician advice, of either supportive care or low-dose cytarabine for the treatment of older patients with newly diagnosed acute myeloid leukemia. J Clin Oncol 30:2670-2677

Kantoff PW, Higano CS, Shore ND, Berger ER, Small EJ et al (2010) Sipuleucel-T immunotherapy for castration-resistant prostate cancer. N Engl J Med 363:411-422

Kassambara A, Klein B, Moreaux J (2009) MMSET is overexpressed in cancers: link with tumor aggressiveness. Biochem Biophys Res Commun 379:840-845

Kaufman HL, Bines SD (2010) OPTIM trial: a Phase III trial of an oncolytic herpes virus encoding GM-CSF for unresectable stage III or IV melanoma. Future Oncol 6:941-949

Khafaei M, Samie S, Mowla SJ, Alvanegh AG, Mirzaei B et al (2015) Evaluation of miR-9 and miR-143 expression in urine specimens of sulfur mustard exposed patients. Interdiscip Toxicol 8:169-174

Khan F, Niaz K, Hassan FI, Abdollahi M (2017a) An evidence-based review of the genotoxic and reproductive effects of sulfur mustard. Arch Toxicol 91:1143-1156

Khan F, Momtaz S, Niaz K, Hassan FI, Abdollahi M (2017b) Epigenetic mechanisms underlying the toxic effects associated with arsenic exposure and the development of diabetes. Food Chem Toxicol 107:406-417

Kohlhapp FJ, Kaufman HL (2016) Molecular pathways: mechanism of action for talimogene laherparepvec, a new oncolytic virus immunotherapy. Clin Cancer Res 22:1048-1054

Korkmaz A, Yaren H, Kunak Z, Uysal B, Kurt B et al (2008) Epigenetic perturbations in the pathogenesis of mustard toxicity; hypothesis and preliminary results. Interdiscip Toxicol 1:236-241

Korkmaz A, Topal T, Aykutlug O, Ates K, Uysal B, et al (2016) Revealing the epigenetic mechanisms on the pathogenesis of lung damage caused by chemical warfare agent mustard analogue mechlorethamine. Toxicol Lett 258:S253

Kupryjańczyk J, Thor AD, Beauchamp R, Merritt V, Edgerton SM et al (1993) p53 gene mutations and protein accumulation in human ovarian cancer. Proc Natl Acad Sci 90:4961-4965

Langevin SM, Kratzke RA, Kelsey KT (2015) Epigenetics of lung cancer. Transl Res 165:74-90

Larkin J, Chiarion-Sileni V, Gonzalez R et al (2015) Combined nivolumab and ipilimumab or monotherapy in untreated melanoma. N Engl J Med 373(1):23-34

Lee LA, Fritz KA, Golitz L, Fritz TJ, Weston WL (1982) Second cutaneous malignancies in patients with mycosis fungoides treated with topical nitrogen mustard. J Am Acad Dermatol 7:590-598

Lee H-Z, Kwitkowski VE, Del Valle PL, Ricci MS, Saber H et al (2015) FDA approval: belinostat for the treatment of patients with relapsed or refractory peripheral T-cell lymphoma. Clin Cancer Res 21:2666-2670

Li H, Chiappinelli KB, Guzzetta AA, Easwaran H, Yen R-WC et al (2014) Immune regulation by low doses of the DNA methyltransferase inhibitor 5-azacitidine in common human epithelial cancers. Oncotarget 5:587-598

Liu G-H, Zhou Z-G, Chen R, Wang M-J, Zhou B et al (2013) Serum miR-21 and miR-92a as biomarkers in the diagnosis and prognosis of colorectal cancer. Tumor Biol 34:2175-2181

Ludlum DB, Mehta JR, Tong WP (1986) Prevention of 1-(3-Deoxycytidyl),2-(1-deoxyguanosinyl)ethane cross-link formation in DNA by rat liver O6-alkylguanine-DNA alkyltransferase. Cancer Res 46:3353-3357

Ma G, Shimada H, Hiroshima K, Tada Y, Suzuki N, Tagawa M (2008) Gene medicine for cancer treatment: commercially available medicine and accumulated clinical data in China. Drug Des Devel Ther 2:115-122
Mann BS, Johnson JR, Cohen MH, Justice R, Pazdur R (2007) FDA approval summary: vorinostat for treatment of advanced primary cutaneous T-cell lymphoma. Oncologist 12:1247-1252

Mezencev R, Kutschy P, Salayova A, Updegrove T, McDonald J (2009) The design, synthesis and anticancer activity of new nitrogen mustard derivatives of natural indole phytoalexin 1-methoxyspirobrassinol. Neoplasma 56:321

Michot JM, Bigenwald C, Champiat S, Collins M, Carbonnel F et al (2016) Immune-related adverse events with immune checkpoint blockade: a comprehensive review. Eur J Cancer 54:139-148

Momparler RL (2005) Epigenetic therapy of cancer with 5-Aza-2'deoxycytidine (decitabine). Semin Oncol 32:443-451

Morera L, Lübbert M, Jung M (2016) Targeting histone methyltransferases and demethylases in clinical trials for cancer therapy. Clin Epigenetics 8:57

Mukaida K, Hattori N, Iwamoto H, Onari Y, Nishimura Y et al (2017) Mustard gas exposure and mortality among retired workers at a poisonous gas factory in Japan: a 57-year follow-up cohort study. Occup Environ Med 74:321-327

Ni R, Zhou J, Hossain N, Chau Y (2016) Virus-inspired nucleic acid delivery system: linking virus and viral mimicry. Adv Drug Deliv Rev 106:3-26

Nieto Y, Valdez BC, Thall PF, Jones RB, Wei W et al (2016) Double epigenetic modulation of high-dose chemotherapy with azacitidine and vorinostat for patients with refractory or poor-risk relapsed lymphoma. Cancer 122:2680-2688

Ning Z-Q, Li Z-B, Newman MJ, Shan S, Wang X-H et al (2012) Chidamide (CS055/HBI-8000): a new histone deacetylase inhibitor of the benzamide class with antitumor activity and the ability to enhance immune cell-mediated tumor cell cytotoxicity. Cancer Chemother Pharmacol 69:901-909

Nishimoto Y, Yamakido M, Ishioka S, Shigenobu T, Yukutake M (1986) Epidemiological studies of lung cancer in Japanese mustard gas workers. Princess Takamatsu Symp 18:95-101

Noman MZ, Buart S, Romero P, Ketari S, Janji B et al (2012) Hypoxiainducible miR-210 regulates the susceptibility of tumor cells to lysis by cytotoxic T cells. Cancer Res 72:4629-4641

O'Connor OA et al (2015) Belinostat, a novel pan-histone deacetylase inhibitor (HDACi), in relapsed or refractory peripheral T-cell lymphoma (R/R PTCL): results from the BELIEF trial. J Clin Oncol 33(23):2492-2501

Odenike O, Green M, Larson R, Rich E, Ott J et al (2008) Phase I study of belinostat (PXD101) plus azacitidine (AZC) in patients with advanced myeloid neoplasms. J Clin Oncol 26:7057

Palucka K, Banchereau J (2013) Dendritic-cell-based therapeutic cancer vaccines. Immunity 39:38-48

Panahi Y, Gholami N, Ghojazadeh M, Moslemi F, Naghavi-Behzad $\mathrm{M}$ et al (2015) omplications and carcinogenic effects of mustard gas-a systematic review and meta-analysis in Iran. Asian Pac J Cancer Prev 16:7567-7573

Pearson S, Jia H, Kandachi K (2004) China approves first gene therapy. Nature Publishing Group, London

Pechura CM, Rall DP (1993) Veterans at risk: the health effects of mustard gas and lewisite. National Academies, Washington

Peirs S, Van der Meulen J, Van de Walle I, Taghon T, Speleman F et al (2015) Epigenetics in T-cell acute lymphoblastic leukemia. Immunol Rev 263:50-67

Pfister SX, Ashworth A (2017) Marked for death: targeting epigenetic changes in cancer. Nat Rev Drug Discov 16(4):241-263

Pio R, Corrales L, Lambris JD (2014) The role of complement in tumor growth. In: Tumor microenvironment and cellular stress. Springer, New York, pp 229-262

Pleyer L, Döhner H, Dombret H, Seymour JF, Schuh AC et al (2017) Azacitidine for front-line therapy of patients with AML: reproducible efficacy established by direct comparison 
of international phase 3 trial data with registry data from the Austrian azacitidine registry of the AGMT study group. Int J Mol Sci 18

Raha P (2016) Outcome of combining epigenetic drugs with other treatments in the clinic. Medical epigenetics: 799-826, pp 799-826

Rajkumar SV, Jacobus S, Callander NS et al (2010) Lenalidomide plus high-dose dexamethasone versus lenalidomide plus low-dose dexamethasone as initial therapy for newly diagnosed multiple myeloma: an open-label randomised controlled trial. Lancet Oncol 11(1):29-37

Ranade AR, Cherba D, Sridhar S, Richardson P, Webb C et al (2010) MicroRNA 92a-2*: a biomarker predictive for chemoresistance and prognostic for survival in patients with small cell lung cancer. J Thorac Oncol 5:1273-1278

Razavi SM, Abdollahi M, Salamati P (2016) Cancer events after acute or chronic exposure to sulfur mustard: a review of the literature. Int J Prev Med 7(1):76

Reddy SA (2016) Romidepsin for the treatment of relapsed/refractory cutaneous T-cell lymphoma (mycosis fungoides/Sézary syndrome): use in a community setting. Crit Rev Oncol Hematol 106:99-107

Richardson PG, Xie W, Mitsiades C et al (2009) Single-agent bortezomib in previously untreated multiple myeloma: efficacy, characterization of peripheral neuropathy, and molecular correlations with response and neuropathy. J Clin Oncol 27(21):3518-3525

Rodriguez PC, Popa X, Martínez O, Mendoza S, Santiesteban E et al (2016) A phase III Clinical trial of the epidermal growth factor vaccine CIMAvax-EGF as switch maintenance therapy in advanced non-small cell lung cancer patients. Clin Cancer Res 22:3782-3790

Rozati S, Cheng PF, Widmer DS, Fujii K, Levesque MP, Dummer R (2016) Romidepsin and azacitidine synergize in their epigenetic modulatory effects to induce apoptosis in CTCL. Clin Cancer Res 22:2020-2031

Saeidnia S, Abdollahi M (2013) Antioxidants: friends or foe in prevention or treatment of cancer: the debate of the century. Toxicol Appl Pharmacol 271:49-63

Saladi R, Smith E, Persaud A (2006) Mustard: a potential agent of chemical warfare and terrorism. Clin Exp Dermatol 31:1-5

San-Miguel JF et al (2014) Panobinostat plus bortezomib and dexamethasone versus placebo plus bortezomib and dexamethasone in patients with relapsed or relapsed and refractory multiple myeloma: a multicentre, randomised, double-blind phase 3 trial. Lancet Oncol 15:1195-1206

San-Miguel J, Hungria V, Yoon S-S, Beksac M, Dimopoulos M et al (2015) Impact of treatment duration and dosing on efficacy and safety in a phase 3 study of panobinostat plus bortezomib and dexamethasone in patients with relapsed or relapsed and refractory multiple myeloma. Clin Lymphoma Myeloma Leuk 15:e270-e271

San-Miguel JF, Hungria VTM, Yoon S-S, Beksac M, Dimopoulos MA et al (2016) Overall survival of patients with relapsed multiple myeloma treated with panobinostat or placebo plus bortezomib and dexamethasone (the PANORAMA 1 trial): a randomised, placebo-controlled, phase 3 trial. Lancet Haematol 3:e506-e15

Sawas A, Radeski D, O'Connor OA (2015) Belinostat in patients with refractory or relapsed peripheral T-cell lymphoma: a perspective review. Ther Adv Hematol. 6:202-208

Schmidt A, Steinritz D, Thiermann H, Meineke V, Abend M (2016) Alteration of miRNA expression in early endothelial cells after exposure with sub-lethal sulfur mustard concentrations. Toxicol Lett 244:88-94

Schmitz N, Trümper L, Ziepert M et al (2010) Treatment and prognosis of mature T-cell and NK-cell lymphoma: an analysis of patients with T-cell lymphoma treated in studies of the German
High-Grade Non-Hodgkin Lymphoma Study Group. Blood 116(18):3418-3425

Scott LJ (2016) Azacitidine: a review in myelodysplastic syndromes and acute myeloid leukaemia. Drugs 76:889-900

Seow Y, Wood MJ (2009) Biological gene delivery vehicles: beyond viral vectors. Mol Ther 17:767-777

Serrone L, Zeuli M, Sega F, Cognetti F (2000) Dacarbazine-based chemotherapy for metastatic melanoma: thirty-year experience overview. Clin Cancer Res CR 19(1):21-34

Seymour JF, Dohner H, Minden MD, Stone R, Gambini D et al (2017) Incidence rates of treatment-emergent adverse events and related hospitalization are reduced with azacitidine compared with conventional care regimens in older patients with acute myeloid leukemia. Leuk Lymphoma 58:1412-1423

Sharma S, Kelly TK, Jones PA (2010) Epigenetics in cancer. Carcinogenesis 31:27-36

Shi Y, Dong M, Hong X, Zhang W, Feng J et al (2015) Results from a multicenter, open-label, pivotal phase II study of chidamide in relapsed or refractory peripheral T-cell lymphoma. Ann Oncol 26:1766-1771

Shinjo K, Kondo Y (2015) Targeting cancer epigenetics: linking basic biology to clinical medicine. Adv Drug Deliv Rev 95:56-64

Simon S (2015) FDA approves Farydak (panobinostat) for multiple myeloma. American Cancer Society. February 25, 2015

Small EJ, Schellhammer PF, Higano CS, Redfern CH, Nemunaitis JJ et al (2006) Placebo-controlled phase III trial of immunologic therapy with Sipuleucel-T (APC8015) in patients with metastatic, asymptomatic hormone refractory prostate cancer. J Clin Oncol 24:3089-3094

Steinritz D, Schmidt A, Balszuweit F, Thiermann H, Simons T et al (2016) Epigenetic modulations in early endothelial cells and DNA hypermethylation in human skin after sulfur mustard exposure. Toxicol Lett 244:95-102

Suchin K, Cucchiara AJ, Gottleib SL et al (2002) Treatment of cutaneous t-cell lymphoma with combined immunomodulatory therapy: a 14-year experience at a single institution. Arch Dermatol 138(8):1054-1060

Sunters A, Springer CJ, Bagshawe KD, Souhami RL, Hartley JA (1992) The cytotoxicity, DNA crosslinking ability and DNA sequence selectivity of the aniline mustards melphalan, chlorambucil and 4-[bis (2-chloroethyl) amino] benzoic acid. Biochem Pharmacol 44:59-64

Takeshima Y, Inai K, Bennett WP, Metcalf RA, Welsh JA et al (1994) p53 mutations in lung cancers from Japanese mustards gas workers. Carcinogenesis 15:2075-2079

Tanaka M, Oikawa K, Takanashi M, Kudo M, Ohyashiki J et al (2009) Down-regulation of miR-92 in human plasma is a novel marker for acute leukemia patients. PLoS One 4:e5532

Thatcher N, Hirsch FR, Luft AV et al (2015) Necitumumab plus gemcitabine and cisplatin versus gemcitabine and cisplatin alone as first-line therapy in patients with stage IV squamous nonsmall-cell lung cancer (SQUIRE): an open-label, randomised, controlled phase 3 trial. Lancet Oncol 16(7):763-774

Thomas XG, Arthur C, Delaunay J, Jones M, Berrak E, Kantarjian HM (2014) A post hoc sensitivity analysis of survival probabilities in a multinational phase III trial of decitabine in older patients with newly diagnosed acute myeloid leukemia. Clin Lymphoma Myeloma Leuk 14:68-72

Tiffon CE, Adams JE, van der Fits L, Wen S, Townsend PA et al (2011) The histone deacetylase inhibitors vorinostat and romidepsin downmodulate IL-10 expression in cutaneous T-cell lymphoma cells. Br J Pharmacol 162:1590-1602

Ungewickell A, Medeiros BC (2012a) Novel agents in acute myeloid leukemia. Int J Hematol 96:178-185

Ungewickell A, Medeiros BC (2012b) Novel agents in acute myeloid leukemia. Int J Hematol 96:178-185 
U.S. Food and Drug Administration (2005) NDA 21-790 approval letter. https://www.accessdata.fda.gov/drugsatfda_docs/ nda/2006/021790s000_Dacogen_Approv.pdf. Accessed 2 May 2006

U.S. Food and Drug Administration (2010), NDA 022393/S-004 approval letter. https://www.accessdata.fda.gov/drugsatfda_docs/ appletter/2011/022393s004ltr.pdf. Accessed 16 Jun 2011

Valizadeh M, Mirzaei B, Tavallaei M, Noorani MR, Amiri M et al (2015) Down-regulation of TGF-b1, TGF-b receptor 2, and TGFb-associated microRNAs, miR-20a and miR-21, in skin lesions of sulfur mustard-exposed Iranian war veterans. J Recept Signal Transduct Res 35:634-639

VanderMolen KM, McCulloch W, Pearce CJ, Oberlies NH (2011) Romidepsin (Istodax, NSC 630176, FR901228, FK228, depsipeptide): a natural product recently approved for cutaneous T-cell lymphoma. J Antibiot 64:525-531

Wada S, Miyanishi M, Nishimoto Y, Kambe S, Miller R (1968) Mustard gas as a cause of respiratory neoplasia in man. Lancet 291:1161-1163

Wheeler GP (1962) Studies related to the mechanisms of action of cytotoxic alkylating agents: a review. Cancer Res 22:651-688

Wijermans P, Lübbert M, Verhoef G, Klimek V, Bosly A (2005) An epigenetic approach to the treatment of advanced MDS; the experience with the DNA demethylating agent 5-aza-2'-deoxycytidine (decitabine) in 177 patients. Ann Hematol 84:9-17
Wirth T, Ylä-Herttuala S (2014) Gene therapy used in cancer treatment. Biomedicines 2:149

Wouters BJ, Delwel R (2016) Epigenetics and approaches to targeted epigenetic therapy in acute myeloid leukemia. Blood 127:42-52

Xia ZJ, Chang JH, Zhang L, Jiang WQ, Guan ZZ et al (2004) Phase III randomized clinical trial of intratumoral injection of E1B gene-deleted adenovirus (H101) combined with cisplatin-based chemotherapy in treating squamous cell cancer of head and neck or esophagus. Chin J Cancer 23:1666-1670

Xie M, Jiang Q, Xie Y (2015) Comparison between decitabine and azacitidine for the treatment of myelodysplastic syndrome: a meta-analysis with 1392 participants. Clin Lymphoma Myeloma Leuk 15:22-28

Yuan C, Xu X-H, Chen Z (2016) Recombinant human adenovirus-p53 therapy for the treatment of nasopharyngeal carcinoma: a metaanalysis. Springerplus 5:1885

Zafarghandi MR, Soroush MR, Mahmoodi M, Naieni KH, Ardalan A et al (2013) Incidence of cancer in Iranian sulfur mustard exposed veterans: a long-term follow-up cohort study. Cancer Causes Control 24:99-105

Zhang S-Y, Lu Y-Y (2012) recombinant adenoviral-p53 Agent (Gendicine): quality control, mechanism of action, and its use for treatment of malignant tumors. In: Liu XY, Pestka S, Shi YF (eds) Recent advances in cancer research and therapy. Elsevier, Netherlands, pp 215-243 